\title{
Levetiracetam for epilepsy: an evidence map of efficacy, safety and economic profiles
}

This article was published in the following Dove Press journal:

Neuropsychiatric Disease and Treatment

\author{
Zhan-Miao $\mathrm{Yi}^{\mathrm{I-3}}$ \\ Cheng Wen ${ }^{1,2}$ \\ Ting $\mathrm{Cai}^{4}$ \\ $\mathrm{Lu} \mathrm{Xu}^{4}$ \\ Xu-Li Zhong ${ }^{5}$ \\ Si-Yan Zhan ${ }^{4,6}$ \\ Suo-Di Zhai ${ }^{1,3}$
}

'Department of Pharmacy, Peking University Third Hospital, Beijing, China; ${ }^{2}$ Department of Pharmacy Administration and Clinical Pharmacy, School of Pharmaceutical Science, Peking University Health Science Center, Beijing, China; ${ }^{3}$ Institute for Drug Evaluation, Peking University Health Science Center, Beijing, China; ${ }^{4}$ Department of Epidemiology and Bio-statistics, School of Public Health, Peking University Health Science Center, Beijing, China; ${ }^{5}$ Department of Pharmacy, Children's Hospital Affiliated to Capital Institute of Pediatrics, Beijing, China; ${ }^{6}$ Center for Clinical Epidemiology, Peking University Third Hospital, Beijing, China
Correspondence: Suo-Di Zhai Department of Pharmacy, Peking University Third Hospital, 49 North Garden Road, Haidian District, Beijing I0019I, China Tel +861082266686

Fax +86 I0 82265740 Email zhaisuodi@।63.com
Objective: To evaluate the efficacy, safety and economics of levetiracetam (LEV) for epilepsy. Materials and methods: PubMed, Scopus, the Cochrane Library, OpenGrey.eu and ClinicalTrials.gov were searched for systematic reviews (SRs), meta-analyses, randomized controlled trials (RCTs), observational studies, case reports and economic studies published from January 2007 to April 2018. We used a bubble plot to graphically display information of included studies and conducted meta-analyses to quantitatively synthesize the evidence.

Results: A total of 14,803 records were obtained. We included 30 SRs/meta-analyses, 34 RCTs, 18 observational studies, 58 case reports and 2 economic studies after the screening process. The included SRs enrolled patients with pediatric epilepsy, epilepsy in pregnancy, focal epilepsy, generalized epilepsy and refractory focal epilepsy. Meta-analysis of the included RCTs indicated that LEV was as effective as carbamazepine (CBZ; treatment for 6 months: $58.9 \%$ vs $64.8 \%$, OR $=0.76,95 \%$ CI: $0.50-1.16$; 12 months: $54.9 \%$ vs $55.5 \%$, OR $=1.24,95 \%$ CI: $0.79-1.93)$, oxcarbazepine ( $57.7 \%$ vs $59.8 \%$, OR=1.34, 95\% CI: 0.34-5.23), phenobarbital $(50.0 \%$ vs $50.9 \%, \mathrm{OR}=1.20,95 \% \mathrm{CI}: 0.51-2.82)$ and lamotrigine (LTG; $61.5 \%$ vs $57.7 \%$, $\mathrm{OR}=1.22,95 \% \mathrm{CI}: 0.90-1.66)$. SRs and observational studies indicated a low malformation rate and intrauterine death rate for pregnant women, as well as low risk of cognitive side effects. But psychiatric and behavioral side effects could not be ruled out. LEV decreased discontinuation due to adverse events compared with $\mathrm{CBZ}(\mathrm{OR}=0.52,95 \% \mathrm{CI}: 0.41-0.65)$, while no difference was found when LEV was compared with placebo and LTG. Two cost-effectiveness evaluations for refractory epilepsy with decision-tree model showed US\$ 76.18 per seizure-free day gained in Canada and US\$ 44 per seizure-free day gained in Korea.

Conclusion: LEV is as effective as CBZ, oxcarbazepine, phenobarbital and LTG and has an advantage for pregnant women and in cognitive functions. Limited evidence supports its cost-effectiveness.

Registered number: PROSPERO (No CRD 42017069367).

Keywords: seizure freedom, responder rate, quality of life, malformations, neurological development, psychiatric side effects, cost-effectiveness

\section{Background}

Epilepsy ranks fourth after tension-type headache, migraine and Alzheimer disease in the world's neurological disorders burden. ${ }^{1}$ A systematic review (SR) and metaanalysis of international studies reported that the point prevalence of active epilepsy was 6.38 per 1,000 people, while the lifetime prevalence was 7.60 per 1,000 people. The annual cumulative incidence of epilepsy was 67.77 per 100,000 people, while the incidence rate was 61.44 per 100,000 person-years. ${ }^{2}$ As a fairly common clinical condition affecting all ages and requiring long-term, sometimes lifelong, treatment, epilepsy incurs high health care costs for the society. ${ }^{1}$ In 2010 , the total annual cost for 
epilepsy was 13.8 billion and the total cost per patient was $€ 5,221$ in Europe. ${ }^{3}$ Meanwhile, in the USA, epilepsy-related costs ranged from $\$ 1,022$ to $\$ 19,749$ per person annually. ${ }^{4}$ What is more, drug-refractory epilepsy was a major cost driver, ${ }^{5}$ with main costs from anticonvulsants, hospitalization and early retirement. ${ }^{6}$

Currently, antiepileptic drugs (AEDs) are the main treatment method for epilepsy patients, and it was reported that approximately two-thirds of epileptic seizures were controlled by AEDs. ${ }^{7}$ Conventional AEDs such as carbamazepine (CBZ) and sodium valproate (VPA) have been proven to have good therapeutic effects and low treatment cost. However, some adverse events (AEs) related to these drugs, such as Stevens-Johnson syndrome, menstrual disorder and memory deterioration seriously affect the tolerance and compliance of patients. Compared with conventional AEDs, new AEDs have the potential to be safer, but also more expensive. ${ }^{8}$

Levetiracetam (LEV) is a novel AED that has been approved as an adjunctive therapy for adults with focal epilepsy since 1999 in the US. In 2006, it was licensed as monotherapy for adults and adolescents above 16 years of age with newly diagnosed focal-onset seizures with or without secondary generalization in Europe. Also, it has been indicated as an adjunctive therapy for partial-onset seizures in patients above 4 years of age in China since 2007. Although the precise mechanism of LEV is still unclear, current researches suggest that its pharmacological mechanism is different from those of other AEDs. It may bind to the synaptic vesicle protein 2A (SV2A), which presents on the synaptic vesicles and some neuroendocrine cells. SV2A may participate in the exocytosis of synaptic vesicles and regulate the release of neurotransmitters, especially the release of excitatory amino acids, and thus depress the epilepsy discharge. ${ }^{9,10}$ Other possible mechanisms of LEV include the following: selective inhibition of voltage-dependent N-type calcium channels in hippocampal pyramidal cells and reduction of the negative allosteric agents' inhibition, such as zinc ions and B-carbolines, on glycine and $\gamma$-aminobutyric acid neurons, which results in indirectly increasing central nervous system inhibition. ${ }^{11}$

LEV is almost completely absorbed after oral administration and the absorption is unaffected by food. The bioavailability is nearly $100 \%$ and the steady-state concentrations are achieved in 2 days if LEV is taken twice daily. Sixty-six percent of LEV is renally excreted unchanged and its major metabolic pathway is enzymatic hydrolysis of the acetamide group, which is independent of liver CYP/ CYP450; so, no clinically meaningful drug-drug interactions with other AEDs were found. ${ }^{12}$ One published SR of LEV suggested LEV has an equal efficacy compared with conventional AEDs and it is well tolerated for long-term therapy without significant effect on the immune system. ${ }^{13}$ But in recent years, apart from the most frequent AEs of LEV, such as nausea, gastrointestinal symptoms, dizziness, irritability and aggressive behavior, some rare AEs of LEV have been reported, including eosinophilic pneumonia, rhabdomyolysis, thrombocytopenia, elevated kinase and reduced sperm quality. ${ }^{14-17}$

Thus, we conducted a mapping review to evaluate the efficacy, safety and economic profiles of LEV compared with all other AEDs for epilepsy, to provide evidence-based information for the rational use of LEV and research agendas.

\section{Materials and methods}

\section{Search strategy}

We searched PubMed, Scopus, Cochrane Central Register of Controlled Trials, ClinicalTrials.gov and OpenGrey.eu from Jan 1, 2007 to April 30, 2017 and updated the search results till April 23, 2018. The following keywords were used in search terms: "anticonvulsant*", "anticonvulsive", "antiepileptic*”, "antiepilepsirin*”, “epileps*”, "epileptic*”, "seizure*", "convulsion*", "trial", "comparative effectiveness research", "cohort study", "case-control study", "case report*”, "case series", "cost-benefit analysis", "cost-effectiveness analysis", "cost-utility analysis", "cost-minimization analysis", "systematic review", "meta-analysis" and "health technology assessment". The search terms "Keppra”, "Levetiracetam", "Desitrend", "Spritam", "Kepcet", "Kevtam" and "Levitam" were used to search relevant literature to LEV. The study was registered on PROSPERO (No CRD 42017069367).

\section{Study selection and outcome measures}

Four independent investigators manually screened the references of all retrieved records for potentially eligible studies through the title and abstract screening in the first stage and the full-text screening in the second. For the title and abstract screening, studies appearing to meet the inclusion criteria or with insufficient information to make a clear judgment, judged by either authors or both, were included in the full-text screening process. We obtained full texts of all these studies for the full-text screening. We included studies if they 1) enrolled patients diagnosed with epilepsy, 2) compared the efficacy, safety or economic profiles of LEV, without restricting to dosage and duration and 3) SR, metaanalysis, randomized controlled trials (RCTs), observational 
studies, case reports and economic studies were considered. We resolved the disagreements through discussion, and if necessary, a third party was consulted and discussed.

The primary efficacy outcomes focused on seizure freedom. The secondary efficacy outcomes included 50\% responder rate, quality of life (QoL), discontinuation due to AEs, serious AEs, total AEs, single AEs and costeffectiveness.

\section{Data extraction and quality assessment}

Data extraction was performed by two independent investigators according to a predesigned data collection form. Extracted information included authors, publication year, search time frame, number of LEV trials, participant characteristic (seizure type, gender and age), intervention information (the dosage and duration), treatment duration, outcome of interest and dropout rate.

Two investigators independently assessed the methodological quality of included studies. We assessed the quality of included SRs using the Assessment of Multiple Systematic Reviews tool (range, $0-11$ ). ${ }^{18} \mathrm{We}$ assessed the risk of bias in the eligible RCTs with the Cochrane risk of bias assessment tool. ${ }^{19}$ The methodological quality of eligible observational studies was evaluated with the Newcastle-Ottawa Scale. ${ }^{20}$ We evaluated the quality of the eligible pharmacoeconomic study with consolidated health economic evaluation reporting standard. ${ }^{21}$ We did not conduct quality assessment of case reports. In the case of missing data, we contacted the authors of eligible studies for clarifications. All disagreements about data extraction and quality assessment were resolved through discussion among all authors.

\section{Statistical analysis}

We compared the treatment effect through meta-analyses in an intention-to-treat manner (following the allocation of participants in studies) of newly included RCTs. Results of RCTs evaluating similar interventions in similar participants were pooled. We calculated the OR for categorical outcomes. We performed meta-analyses of newly included RCTs with RevMan 5.3 software using random-effect model. Statistical heterogeneity was assessed with the Mantel-Haenszel chisquared test and quantified with the $I^{2}$ test. $P<0.05$ was considered statistically significant. Analyses of evidence mapping were conducted in $\mathrm{R}$ version 3.4.3. We used a bubble plot to graphically display the evidence regarding seizure type, control vs LEV and outcome measures. Seizure type was classified based on the type of patients and type of epilepsy. Controls were classified based on the class of antiepileptic drug. Outcomes were classified into efficacy and safety outcomes. The number of included studies in SRs and the number of included patients in RCTs were presented as the size of the circles. We described the safety outcomes of observational studies and pooled the numbers of case reports by classification of diseases.

\section{Results \\ Study selection}

The initial search identified 14,803 relevant records and the updated search identified 694 records. Also, 11,801 records remained after duplicates were removed. Of these, 10,455 records were excluded after LEV search and title/abstract screening and 162 reports were eligible for full-text review. After full-text review, we included 142 reports: 30 SRs/metaanalyses, ${ }^{22-51} 34 \mathrm{RCTs},{ }^{52-85} 18$ observational studies, ${ }^{86-103}$ 58 case reports ${ }^{104-161}$ and 2 economic studies ${ }^{162,163}$ (Figure 1).

\section{Study characteristics and quality assessment}

The included SRs were published between 2007 and 2018, enrolling patients with pediatric epilepsy, epilepsy in pregnancy, focal epilepsy, generalized epilepsy and refractory focal epilepsy. Twenty SRs compared LEV with placebo, ${ }^{22-35,38,40,44,46,49,50} 19$ SRs compared LEV with other AEDs $^{23,24,30,34,36-43,45-51}$ and 8 SRs were network meta-analyses that compared LEV with other AEDs ${ }^{23,30,37,45-48,50}$ as well as placebo. ${ }^{23,30,46,50}$ Outcome measures included seizure freedom, $50 \%$ responder rate, reduction in seizure frequency, neuropsychological findings, congenital malformation, serious AEs, total AEs, single AEs and other outcomes (Figure 2A).

Among the included RCTs, 12 compared LEV with placebo, ${ }^{52,55,56,58,60-63,65,66,68,78} 9$ compared LEV with CBZ, ${ }^{53,69,70,73,74,79-82} 4$ compared LEV with lamotrigine (LTG), ${ }^{57,64,71,81} 3$ compared LEV with phenobarbital (PB), ${ }^{64,75,85} 3$ compared LEV with VPA, ${ }^{70,74,82} 2$ compared LEV with oxcarbazepine (OXC), ${ }^{54,83} 2$ compared LEV with sulthiame, ${ }^{72,84} 1$ compared LEV with pregabalin, ${ }^{77} 1$ compared LEV with phenytoin ${ }^{59}$ and 1 compared LEV with topiramate. ${ }^{67}$ Outcome measures included seizure freedom, $50 \%$ responder rate, reduction in seizure frequency, QoL, serious AEs, total AEs, single AEs and other outcomes (Figure 2B).

The two economic studies were from Canada and Korea, both of which focus on add-on therapy for refractory epilepsy. ${ }^{162,163}$ The two studies used a decision-tree model from the social perspective and payer perspective, respectively. 


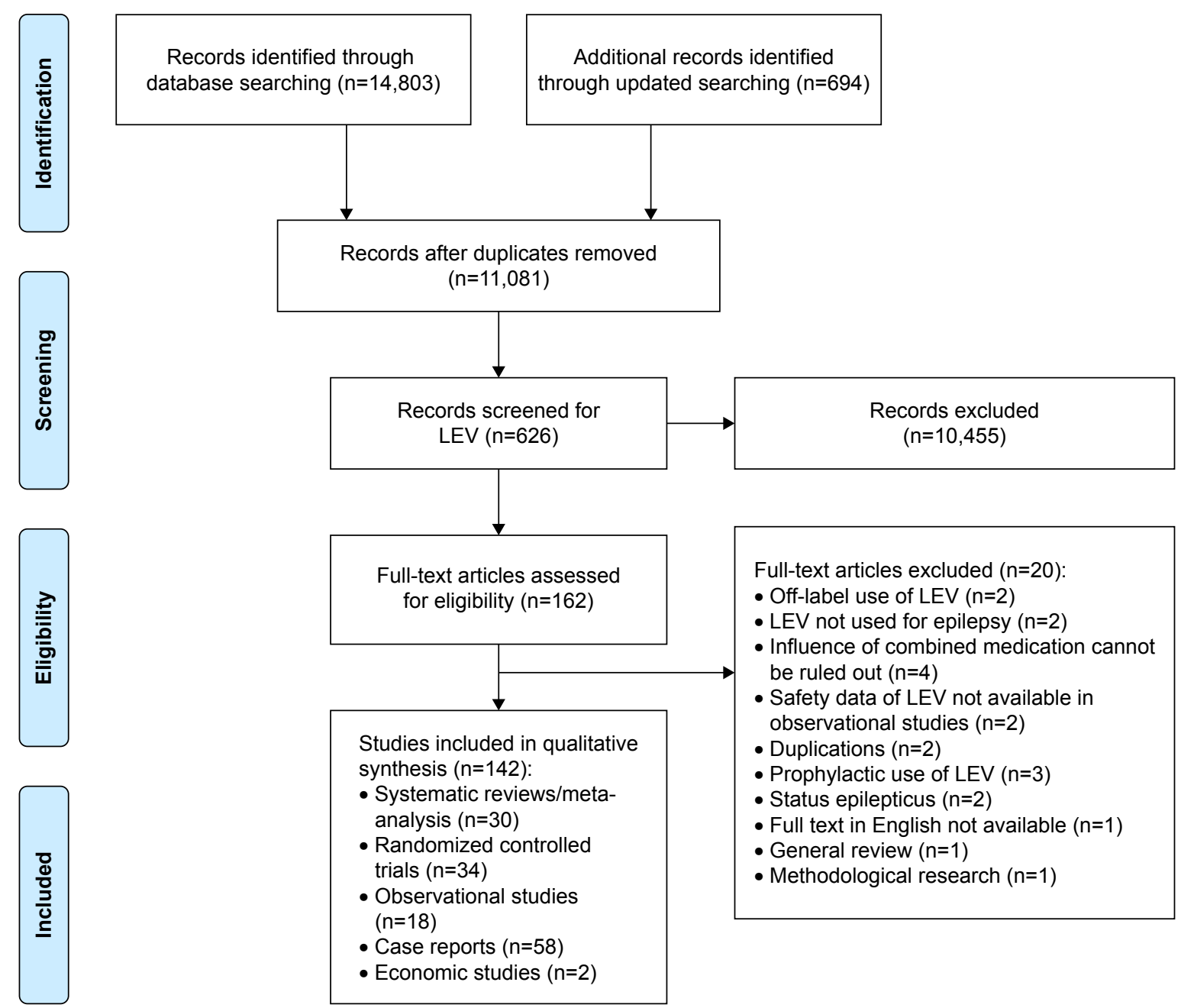

Figure I Flow diagram for literature search and study selection.

Abbreviation: LEV, levetiracetam.

Study characteristics of the included observational studies and case reports are shown in Tables 1 and 2, respectively.

In general, the quality of included SRs and economic studies was good. The included RCTs were generally of low risk of bias. Sixteen RCTs used the double-blind design and 24 adopted the intention-to-treat principle to analyze data (Table 3).

\section{Efficacy}

\section{Seizure freedom}

Thirteen SRs evaluated rates of seizure freedom ${ }^{23,26,31,37,40,41 \text {, }}$ 43-46,49-51 (Figure 2A) and indicated that LEV increased the rates of seizure freedom compared with placebo, ${ }^{23,26,31,40,44,46,49,50}$ but there was no difference when LEV was compared with OXC, ${ }^{41,49} \mathrm{LTG}^{23,37,45,51}$ and brivaracetam. ${ }^{40}$

Meta-analysis of newly included RCTs indicated that LEV increased the rates of seizure freedom compared with placebo $(19.2 \%$ [121/629] vs $3.4 \%$ [19/565], OR=5.42,
95\% CI: 3.27-8.98). Meta-analyses of newly included RCTs showed that there was no difference when LEV was compared with CBZ (treatment for 6 months: 58.9\% [567/963] vs 64.8\% [629/970], OR=0.76, 95\% CI: 0.50-1.16; treatment for 12 months: $54.9 \%$ [538/980] vs $55.5 \%$ [560/1,009], OR $=1.24,95 \%$ CI: $0.79-1.93)$, OXC (57.7\% [112/194] vs $59.8 \%$ [113/189], OR=1.34, 95\% CI: 0.34-5.23), PB (50.0\% [31/62] vs $50.9 \%$ [27/53], OR=1.20, 95\% CI: $0.51-2.82$ ) and LTG $(61.5 \%$ [225/366] vs $57.7 \%$ [202/350], OR=1.22, 95\% CI: 0.90-1.66). We observed significant heterogeneity across included studies in the subgroup of CBZ ( $I^{2}=74 \%$ for 6 months treatment and $I^{2}=76 \%$ for 12 months treatment), as shown in Figure 3A.

\section{$\geq 50 \%$ responder rates}

Sixteen SRs evaluated $\geq 50 \%$ responder $\operatorname{rates}^{23,24,26,27,29-31 \text {, }}$ 36,40-43,46,49-51 (Figure 2A) and 12 SRs indicated that LEV increased the rates of $\geq 50 \%$ responder rates compared with 
A

(E)-reduction in seizure frequency (E)-quality of life
$\%$ responder rate (E)-50\% responder rate

(S)-decreased white blood cells

(S)-increased cough

(S)-decreased platelets
(S)-anxiety

\begin{tabular}{rr} 
gै & $\begin{array}{r}(\mathrm{S}) \text {-rhinitis } \\
\text { (S)-nausea }\end{array}$ \\
\hline 0 & (S)-abnormal behavior
\end{tabular}

(S)-infection

(S)-flu syndrome

(S)-agitation (S)-asthenia

(S)-accidents and injuries (S)-total AEs

(S)-somnolence

(S)-tolerability

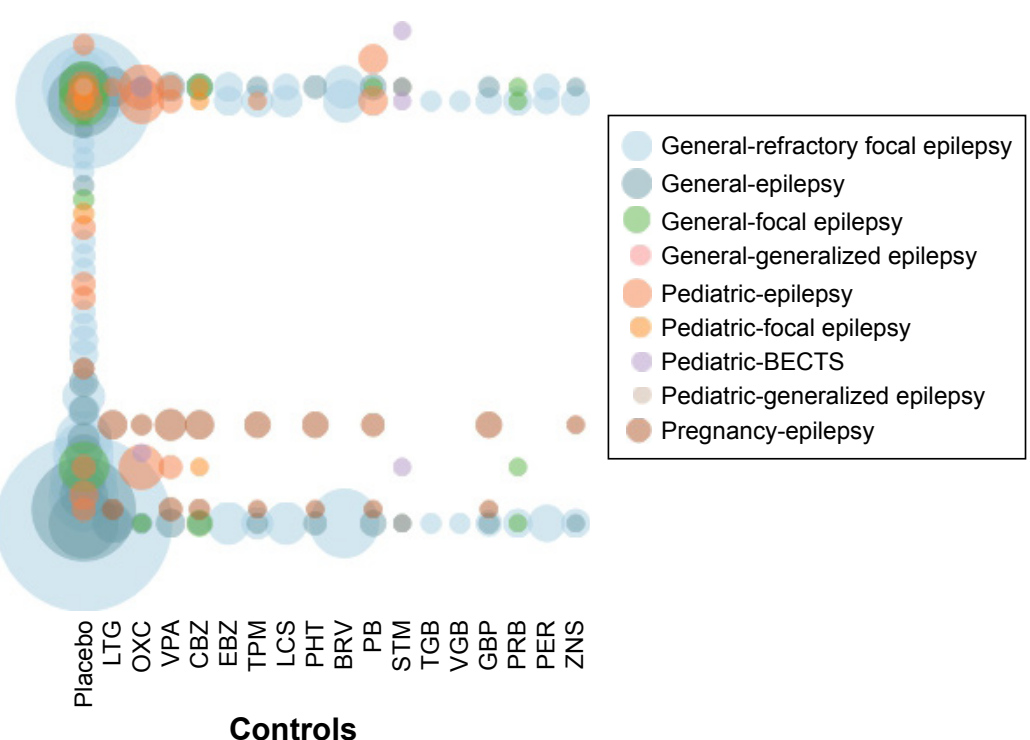

B

(E)-electroencephalogram

(E)-reduction in seizure frequency

(E)-50\% responder rate

(E)-quality of life

(E)-seizure freedom

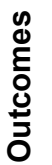

(S)-PR and QTc intervals

(S)-bone health

(S)-serious AEs

(S)-neuropsychological findings

(S)-single AEs

(S)-tolerability

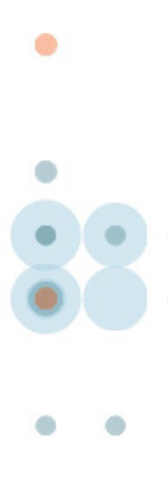

:

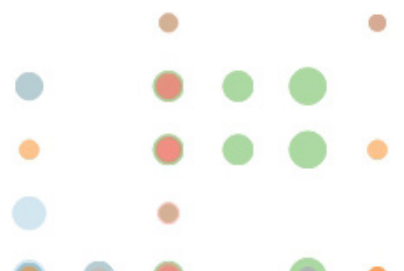

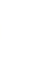




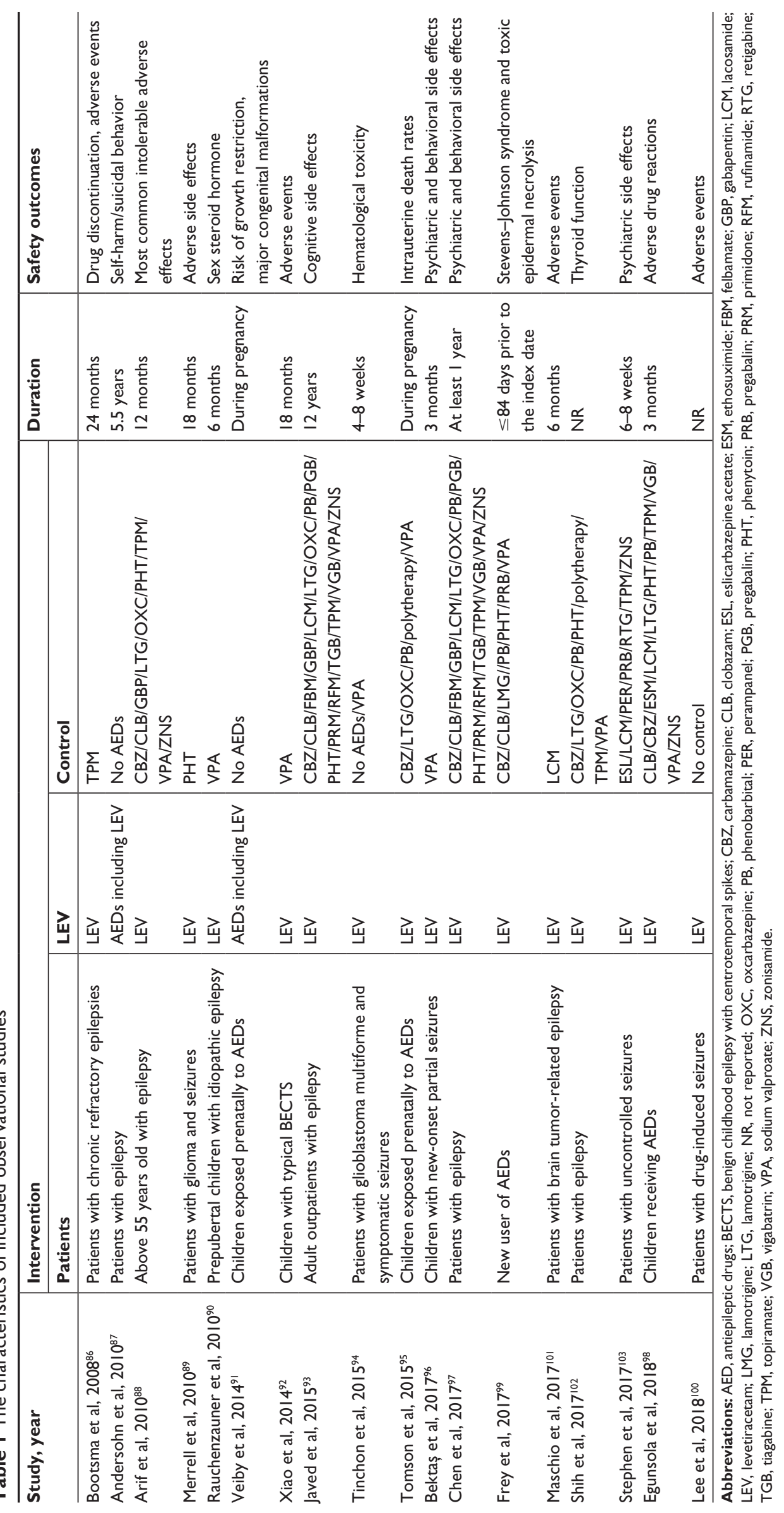




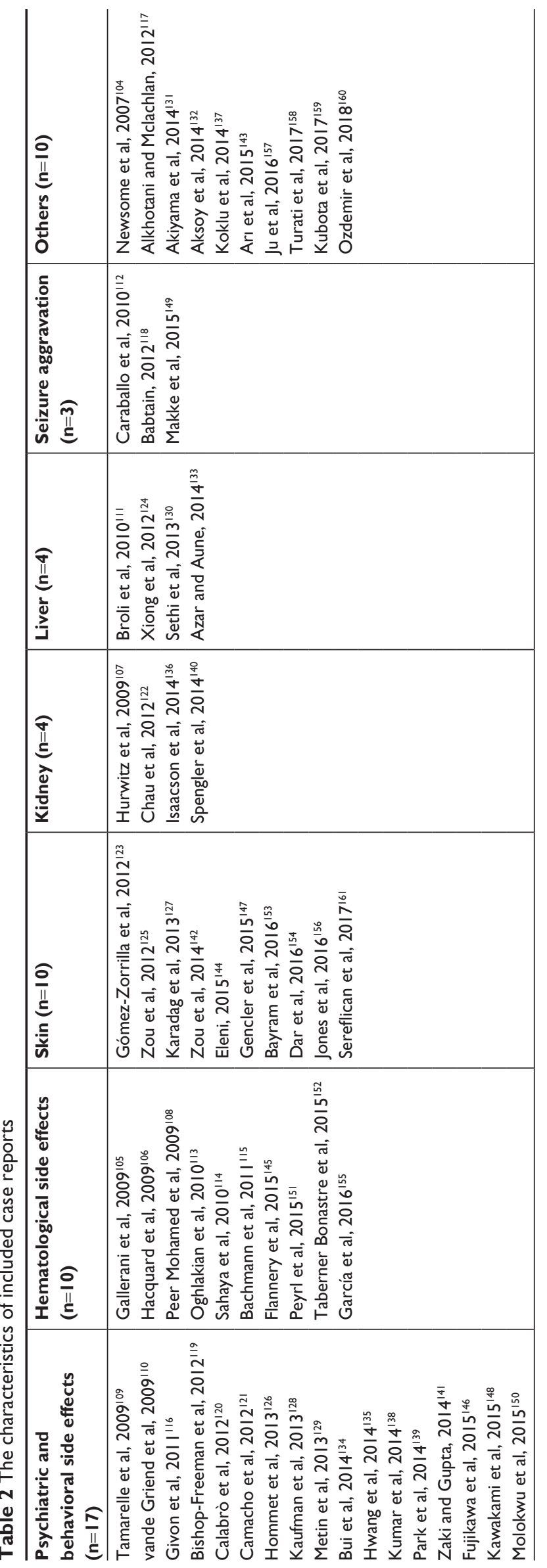

Meta-analysis of newly included RCTs indicated that LEV decreased discontinuation due to AEs compared with CBZ (OR $=0.52,95 \%$ CI: $0.41-0.65$ ), while there was no difference when LEV was compared with placebo $(\mathrm{OR}=1.16$, 95\% CI: 0.92-1.46) and LTG (OR=1.24, 95\% CI: 0.55-2.83). We observed significant heterogeneity $\left(I^{2}=74 \%\right)$ across included studies in the subgroup of LTG.

\section{Serious AEs}

Meta-analysis of newly included RCTs showed that there was no difference when LEV was compared with placebo $(\mathrm{OR}=1.10,95 \%$ CI: $0.59-2.05), \mathrm{CBZ}(\mathrm{OR}=0.83,95 \% \mathrm{CI}$ : $0.35-1.95)$ and LTG (OR=1.40, 95\% CI: $0.74-2.62)$ in the rates of serious AEs.

\section{Total AEs}

SRs indicated that AEs were not significantly different between the LEV group and the placebo group. ${ }^{31}$

Meta-analysis of newly included RCTs showed that there was no difference when LEV was compared with placebo $(\mathrm{OR}=1.16,95 \% \mathrm{CI}: 0.92-1.46)$ and $\mathrm{OXC}(\mathrm{OR}=0.73,95 \% \mathrm{CI}$ : $0.47-1.15)$ in the rates of total AEs.

\section{Single AEs}

\section{Malformations and prenatal outcomes}

Two SRs reported the safety of AEDs during pregnancy, both of which indicated that LEV was not associated with a higher risk compared to control ( $\mathrm{RR}=0.32,95 \% \mathrm{CI}$ : $0.10-1.07$ and $\mathrm{OR}=0.72,95 \%$ CI: $0.43-1.16$, respectively). ${ }^{39,47}$

Two observational studies used data from deliveries recorded in the compulsory Medical Birth Registry of Norway 1999-2011 and International Registry of Antiepileptic Drugs and Pregnancy (EURAP) registry, respectively. ${ }^{91,95}$ While data in the Norway registry showed LEV had a low malformation rate for pregnant women $(\mathrm{OR}=0.63,95 \% \mathrm{CI}$ : $0.16-2.55$ for monotherapy and OR=1.08, 95\% CI: $0.27-$ 4.43 for polytherapy), data in the EURAP registry indicated low intrauterine death rates $(8.6 \%, 95 \% \mathrm{CI}: 5.8 \%-12.3 \%)$.

\section{Neurological development}

One SR showed that LEV did not increase the risk for delayed development of children (cognitive development delay: OR=3.42, 95\% Credible Interval: 0.65-16.40; psychomotor development delay: $\mathrm{OR}=0.27,95 \%$ Credible Interval: $0.00-4.65) .^{48}$

An observational study by Javed et $\mathrm{al}^{93}$ indicated a low risk of cognitive side effects of LEV (OR $=0.68,95 \%$ CI: $0.48-0.99$ in patients newly started on polypharmacy). 
Table 3 Risk of bias of included randomized controlled trials

\begin{tabular}{|c|c|c|c|c|c|c|}
\hline Study, year & $\begin{array}{l}\text { Random sequence } \\
\text { generation }\end{array}$ & $\begin{array}{l}\text { Allocation } \\
\text { concealment }\end{array}$ & Blinding & $\begin{array}{l}\text { Incomplete } \\
\text { outcome data }\end{array}$ & $\begin{array}{l}\text { Selecting } \\
\text { reporting }\end{array}$ & $\begin{array}{l}\text { Other source } \\
\text { of bias }\end{array}$ \\
\hline Berkovic et al, $2007^{52}$ & Low & Low & Low & Low & Low & High \\
\hline Borggraefe et al, $2013^{72}$ & Low & Low & Low & Low & Unclear & Unclear \\
\hline Brodie et al, $2007^{53}$ & Unclear & Unclear & Low & Low & Low & Unclear \\
\hline Consoli et al, $2012^{69}$ & Low & High & High & Low & Unclear & Low \\
\hline Coppola et al, $2007^{54}$ & Low & High & High & Low & Unclear & Unclear \\
\hline Cumbo and Ligori, $2010^{64}$ & Unclear & Unclear & Low & Low & Unclear & Low \\
\hline de La Loge et al, $2010^{65}$ & Unclear & Unclear & Low & Low & Low & High \\
\hline Fattore et al, 20I I ${ }^{68}$ & Low & Unclear & Low & Low & Unclear & Unclear \\
\hline Hakami et al, $2016^{82}$ & Low & Unclear & High & Low & Low & Low \\
\hline Hakami et al, $2012^{70}$ & Low & Unclear & High & Low & Low & Low \\
\hline Inoue et al, $2015^{78}$ & Unclear & Unclear & Low & Low & Low & Unclear \\
\hline Labiner et al, $2009^{57}$ & Unclear & Unclear & Low & Low & Unclear & Low \\
\hline Jung et al, $2015^{79}$ & Low & Low & High & Unclear & Low & Low \\
\hline Kim et al, $2017^{83}$ & Unclear & Unclear & High & Unclear & Low & Unclear \\
\hline Levisohn et al, $2009^{58}$ & Low & Unclear & Low & Low & Low & High \\
\hline Lim et al, $2009^{59}$ & Low & Unclear & Unclear & Low & Unclear & Unclear \\
\hline Peltola et al, $2009^{60}$ & Unclear & Unclear & Low & Low & Low & High \\
\hline Piña-Garza et al, $2009^{61}$ & Unclear & Unclear & High & Unclear & Low & Unclear \\
\hline Rosenow et al, $2012^{71}$ & Low & Unclear & High & Low & Low & Low \\
\hline Rossetti et al, $2014^{76}$ & Low & Low & High & Low & Low & Unclear \\
\hline Siniscalchi et al, $2014^{85}$ & Unclear & Unclear & High & Low & Unclear & Low \\
\hline Suresh et al, $2015^{80}$ & Unclear & Unclear & High & Unclear & Low & Low \\
\hline Tacke et al, $2017^{84}$ & Low & Low & Low & Unclear & Low & Unclear \\
\hline Trinka et al, $2013^{74}$ & Low & Low & High & Unclear & Low & High \\
\hline Werhahn et al, $2015^{81}$ & Low & Low & Low & Low & Low & Low \\
\hline Wu et al, $2009^{62}$ & Unclear & Unclear & Low & Low & Low & Low \\
\hline Xiao et al, $2009^{63}$ & Low & Low & Low & Low & Unclear & Unclear \\
\hline Zaccara et al, $2014^{77}$ & Low & Unclear & Low & Low & Low & Unclear \\
\hline Zhou et al, $2008^{56}$ & Low & Unclear & High & Unclear & Unclear & Unclear \\
\hline Noachtar et al, $2008^{55}$ & Low & Low & Low & Low & Low & Unclear \\
\hline NCTOI $228747^{66}$ & Unclear & Unclear & Low & Low & Low & Unclear \\
\hline NCT019828I $2^{75}$ & Unclear & Unclear & High & Low & Low & Low \\
\hline NCT0I954I $\left.2\right|^{73}$ & Unclear & Unclear & High & Low & Low & Unclear \\
\hline NCTOI $229735^{67}$ & Unclear & Unclear & High & Low & Low & Unclear \\
\hline
\end{tabular}

Psychiatric and behavioral side effects (PBSEs)

One SR showed from various types of studies that LEV administration was associated primarily with adverse psychotropic effects including anxiety, irritability and depression. ${ }^{28}$ One $\mathrm{SR}^{32}$ indicated that $\mathrm{LEV}$ increased the risk of developing several behavioral side effects ( $R R=2.18,95 \%$ CI: $1.42-3.37$ ) such as aggression, hostility and nervousness, while the other SR reported lower rates of behavioral effects. ${ }^{33}$ Another SR indicated that LEV may have a relationship with suicidality in epilepsy (Figure 2A). ${ }^{34}$

Meta-analysis of newly included RCTs indicated that LEV increased the risk of irritability compared with placebo $(n=328, O R=11.55,95 \%$ CI: 2.12-62.90; Figure 4A $)$ and the risk of depression compared with $\mathrm{CBZ}(\mathrm{n}=1,564, \mathrm{OR}=2.18$, 95\% CI: 1.24-3.82; Figure 4B). But no difference was found in the risk of depression when LEV was compared with LTG $(\mathrm{n}=673, \mathrm{OR}=1.80,95 \%$ CI: 0.82-3.97).

For observational studies, Bootsma et $\mathrm{a}^{86}$ indicated the most prevalent AEs for LEV were activating mood disorders (8.1\% for 6 months, $5.2 \%$ for 12 months and $10.6 \%$ for 18 months), Arif et al ${ }^{88}$ indicated psychiatric AEs were the most common adverse effects leading to intolerability and Andersohn et $\mathrm{al}^{87}$ indicated LEV was associated with an increased risk of self-harm or suicidal behavior. Chen et al ${ }^{97}$ 


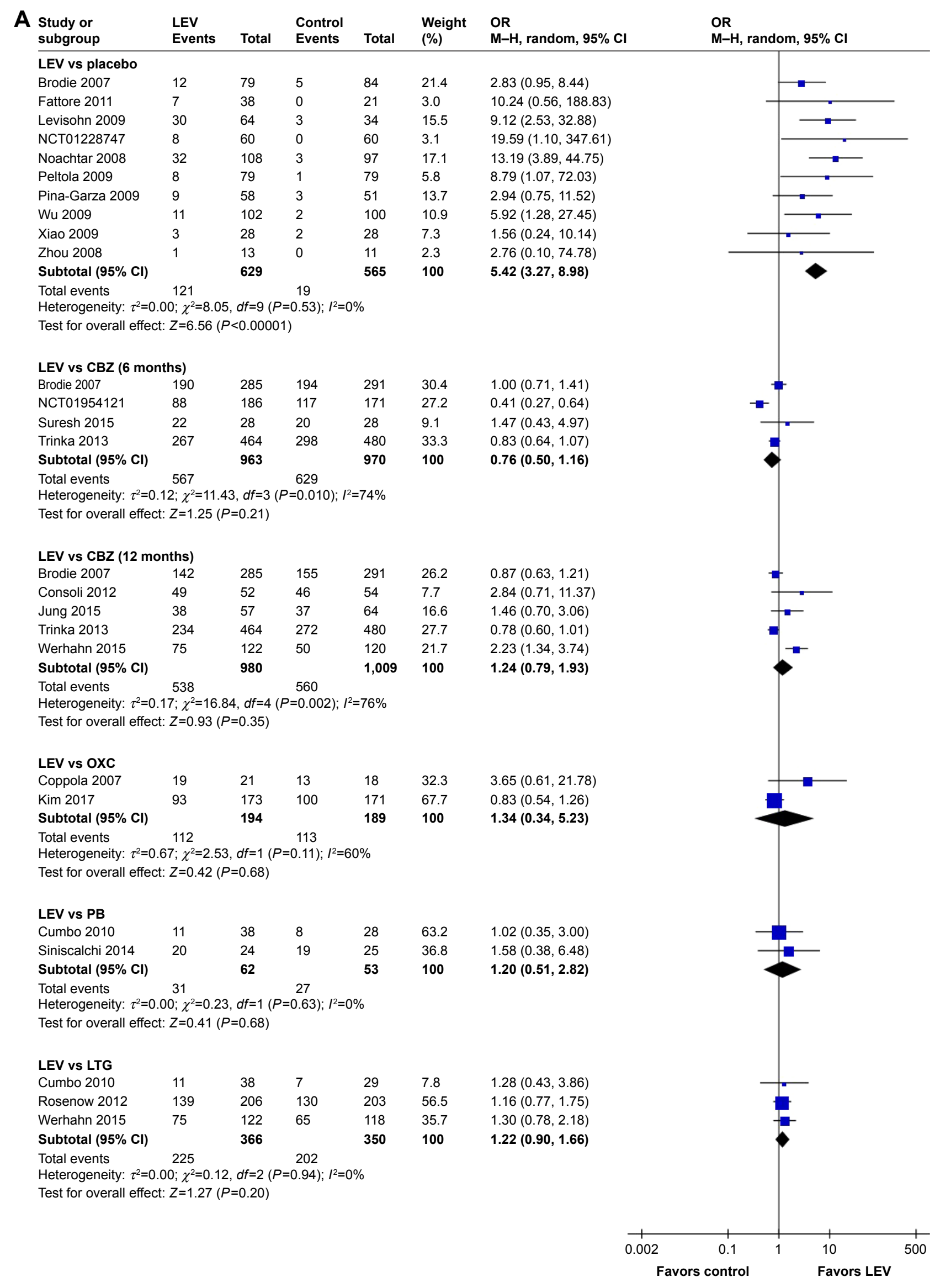

Figure 3 (Continued) 


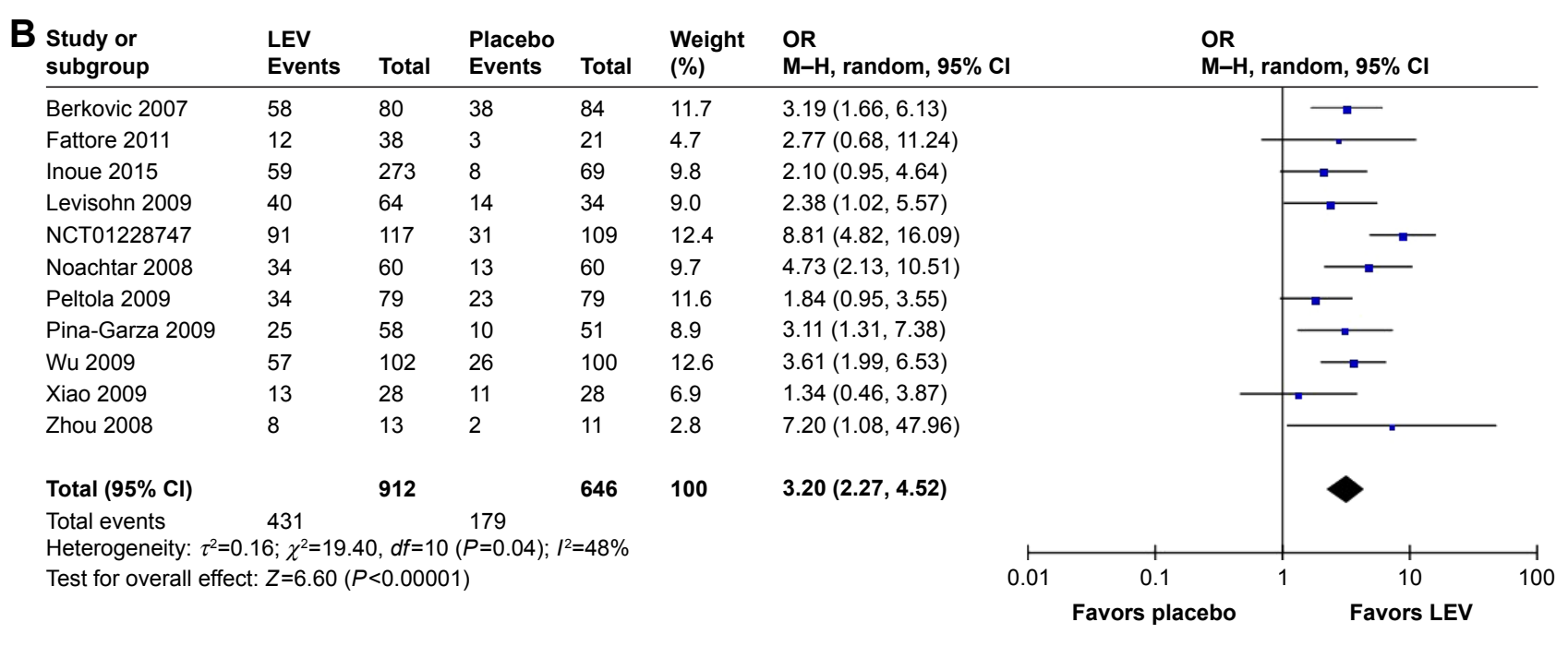

Figure 3 Rate of seizure freedom of included randomized controlled trials $(\mathbf{A})$ and $\geq 50 \%$ responder rates of included randomized controlled trials $(\mathbf{B})$.

Abbreviations: CBZ, carbamazepine; $d f$, degrees of freedom; LEV, levetiracetam; LTG, lamotrigine; M-H, Mantel-Haenszel; OXC, oxcarbazepine; PB, phenobarbital; random, random-effect model.

indicated that LEV had the greatest PBSE rate in adults with epilepsy. However, Bektaş et al ${ }^{96}$ indicated that psychosocial and behavioral side effects of LEV treatment are not frequent and they do not emerge in most of the children at lower doses, and Stephen et $\mathrm{al}^{103}$ indicated a lower rate of psychiatric side effects for LEV than sodium channel blocking AEDs.

Among the 58 case reports, 17 reported PBSEs, including depression, suicidality and hypersexuality.

\section{Other AEs}

SRs indicated that LEV did not increase the risk of imbalance, ${ }^{22}$ but increased the risk of diplopia (Figure 2A). ${ }^{25}$

Meta-analysis of newly included RCTs indicated LEV had a lower risk of leukopenia (OR $=0.13,95 \% \mathrm{CI}$ : $0.02-0.72)$, rash (OR=0.42, 95\% CI: $0.25-0.73)$, increased liver parameters $(\mathrm{OR}=0.19,95 \% \mathrm{CI}: 0.08-0.46)$ and nausea $(\mathrm{OR}=0.69,95 \% \mathrm{CI}: 0.49-0.97)$ compared with $\mathrm{CBZ}$ (Figure 4B). LEV had a lower risk of nausea $(\mathrm{OR}=0.62$, 95\% CI: $0.39-0.98)$ and a higher risk of fatigue $(\mathrm{OR}=1.87$, 95\% CI: 1.26-2.77) compared with LTG. Meta-analyses of newly included RCTs showed that there was no difference when LEV was compared with placebo, CBZ, LTG and OXC in headache (Figure 4A). No difference was found in somnolence and dizziness when LEV was compared with placebo, CBZ and LTG (Figure 4A).

Among the observational studies, Merrell et al indicated LEV had fewer side effects than phenytoin. ${ }^{89}$ Rauchenzauner et al indicated LEV did not seem to induce changes in reproductive endocrine functions and clinically relevant endocrine side effects in prepubertal children. ${ }^{90}$ Tinchon et al indicated LEV has no additional impact on mediumterm hematological toxicity in glioblastoma multiforme patients. ${ }^{94}$ Xiao et al reported all AEs of LEV were either mild or transient and thus did not lead to withdrawal from drug treatment. ${ }^{92}$

Other case reports were related to side effects in the hematological system, skin, kidney, liver and other systems (Table 2).

\section{Cost-effectiveness}

Two cost-effectiveness evaluations for refractory epilepsy with the decision-tree model were conducted in Canada and Korea, respectively.

The Canadian study showed the incremental costeffectiveness ratio (ICER) was US\$ 76.18 per seizure-free day (SFD) gained for the base-case scenario; when the cost of surgical investigation and surgery was included in the model, the ICERs decreased to US\$ 39.18 , which was the most cost-effective situation. ${ }^{162}$

The Korean study showed that LEV add-on therapy gained 18.3 SFDs per patient per year and the ICERs were US\$ 44 per SFD per patient and US\$ 11,084 per quality-adjusted life year gained from the third-party payer perspective. ${ }^{163}$

\section{Discussion}

In our evidence map, the included SRs and newly conducted meta-analyses showed consistent results regarding clinical benefits and potential harms of LEV. Our evidence map indicated that LEV had similar efficacy in seizure freedom compared with conventional AEDs and was superior to placebo in seizure freedom and $\geq 50 \%$ responder rates. What is more, LEV had a lower risk of discontinuation due to AEs compared with $\mathrm{CBZ}$ and did not increase the risk of malformations and prenatal outcomes as well as neurological 


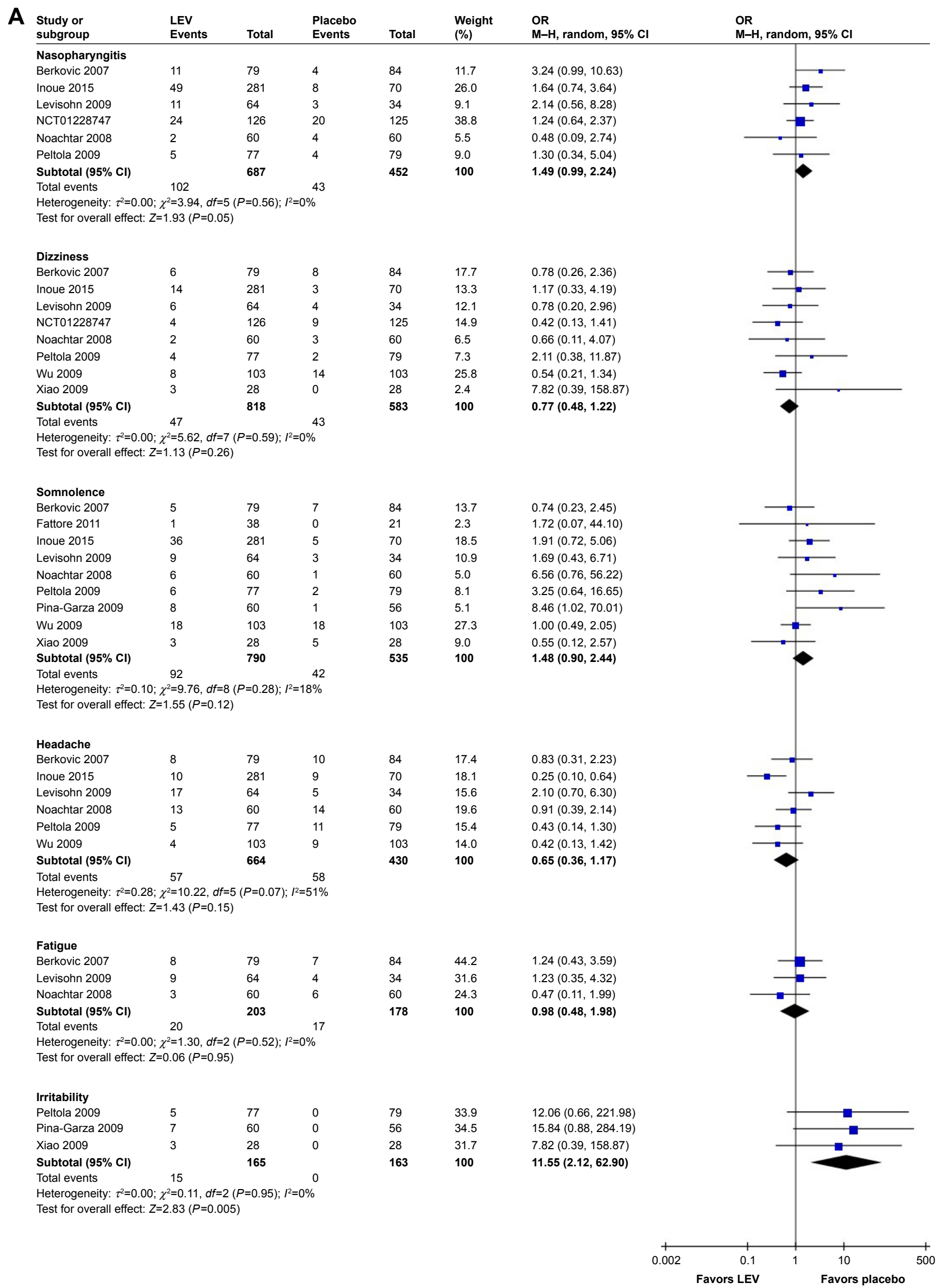

Figure 4 (Continued) 


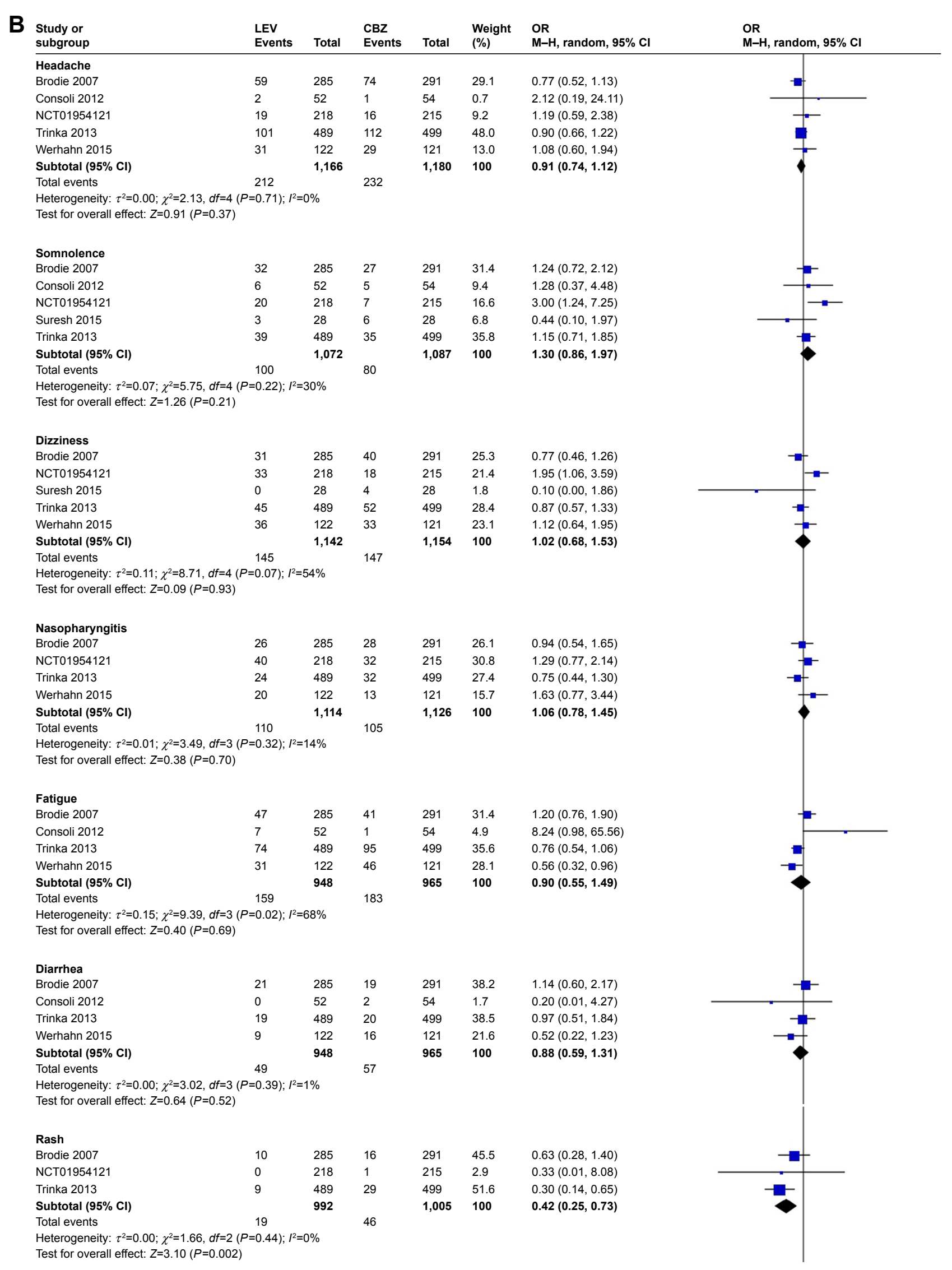

Figure 4 (Continued) 


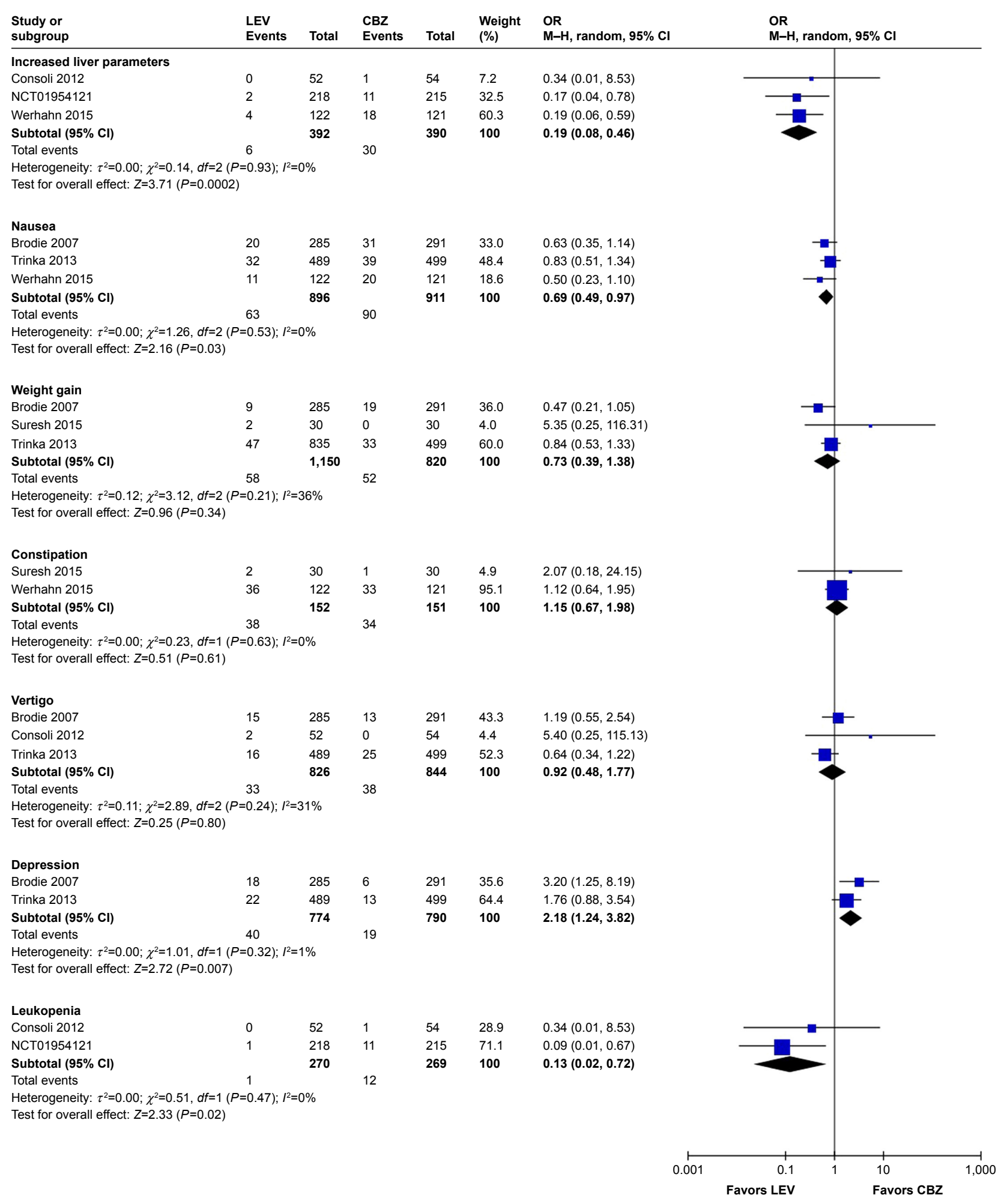

Figure 4 Risk of single adverse events (LEV vs placebo, A; LEV vs CBZ, B).

Abbreviations: CBZ, carbamazepine; $d f$, degrees of freedom; LEV, levetiracetam; M-H, Mantel-Haenszel; random, random-effect model.

development. Limited evidence suggested it was costeffective in certain settings.

LEV has been classified by the US Food and Drug Administration as a category $\mathrm{C}$ drug, with the caution that it should be used during pregnancy only if the potential benefit justifies the potential risk to the fetus. A Cochrane review included in our study analyzed the incidence of congenital malformations in pregnant women during AED treatment and 
reported that LEV and LTG exposure carried the lowest risk of overall malformation. ${ }^{39}$ A recently published prospective cohort study based on the EURAP international registry reported the lowest prevalence of major congenital malformations of $\operatorname{LEV}(2.8 \%, 17 / 599$ pregnancies $)$ compared with other seven commonly used AEDs. ${ }^{164}$ Two observational studies $^{91,95}$ included in this evidence map drew similar conclusions. A published study found that compared with VPA, LEV did not cause apoptosis in immature rat brain neurons, which may be the reason of its safety for pregnant women. ${ }^{165}$ Neurologists are also concerned with the effect of AEDs on cognitive function, which significantly affects the QoL of patients, especially children and the elderly. No AEs of LEV on cognitive function were found in our study, which was consistent with the guidelines. However, there are some RCTs, observational studies and case reports indicating the AEs of mood disorders of LEV. We should monitor these AEs during the course of medication.

A number of guidelines included LEV as a main drug for antiepileptic treatment. The National Institute for Health and Care Excellence (NICE; 2017) recommended that LEV could be used as a monotherapy and in the adjunctive treatment of focal epilepsy (with or without secondary generalization) and adjunctive therapy of myoclonic seizures in patients with juvenile myoclonic epilepsy and generalized tonic clonic seizures. ${ }^{7}$ The Scottish Intercollegiate Guidelines Network gave a similar recommendation and further suggested that LEV or LTG may be a reasonable alternative for women of childbearing age. Moreover, the guideline also suggested that LEV was better tolerated than sustained-release CBZ in poststroke seizures and produced fewer cognitive AEs than LTG or PB in the elderly with epilepsy and Alzheimer disease. ${ }^{166}$ The Biopharmaceutics Drug Disposition Classification System predicted that the risk of skin rash by LEV is not as high as by CBZ or LTG, ${ }^{167}$ and that human leukocyte antigen testing is not necessary. With the increasing number of studies on LEV, guideline recommendations need to update the evidence for LEV. ${ }^{168}$ Our research provides supplements for evidence update in future guidelines.

The economic evaluation of LEV showed that LEV appeared to be cost-effective when the costs of surgical investigation were discounted. Besides, when LEV is added to the usual treatment of patients with refractory epilepsy, the increase in drug costs may at least be partially offset by savings in other medical costs due to an increase in SFDs and improvement of QoL. ${ }^{169}$ But until now, the NICE guideline still has suggested LEV monotherapy as a second-line drug and LEV is considered when the standard first-line drugs such as CBZ and LTG are unsuitable or develop intolerance in the newly diagnosed focal seizure. The economic profiles of our research can help with the cost-effectiveness decision making in certain conditions.

To the best of our knowledge, this study is the most comprehensive evidence of LEV in the following aspects. First, we included various types of studies, such as high-quality RCTs, cohort studies, observational studies, case reports and economic studies. The literature included was comprehensive and involved a large number of patients. Second, we evaluated the clinical application of LEV from three dimensions: efficacy, safety and economy, while the three aspects were studied respectively or the evaluation of LEV was among the overall evaluation of a variety of AEDs in the previous published studies. ${ }^{30,36,163,170}$ Thus, our study can provide comprehensive evidence of LEV for physicians or policymakers.

Our study still had some limitations. First, only English language studies were included. We tried to include important conference abstracts found in the databases, but failed to find relevant studies. Moreover, the literature included in this study was published after 2007, although previously published studies were included in the SRs of the evidence map. Third, some special types of seizures such as status epilepticus (SE) were excluded and data of LEV in special populations were not assessed separately. Fourth, no subgroup analysis of different types of seizures and/or epilepsy syndromes was conducted.

The NICE guideline suggested that LEV is potentially as effective as PB and safer for SE. Currently available intravenous AEDs are limited, and intravenous LEV may have advantages for patients who cannot be administered orally with SE or in the perioperative period. ${ }^{171,172} \mathrm{~A}$ chart review in Germany showed LEV was the first choice for intravenous treatment of SE compared with valproate, phenytoin and lacosamide. ${ }^{173}$ We can evaluate the role of LEV for SE in future studies.

\section{Conclusion}

LEV has been applied for diverse epilepsies, and the evidence map shows that it increases the rates of seizure freedom and $\geq 50 \%$ responder rates compared with placebo, has similar efficacy with CBZ, OXC, PB and LTG, and also has an advantage for pregnant women as well as in cognitive functions. LEV does not increase the risks of serious AEs and discontinuation from studies due to AEs. Limited evidence supports its cost-effectiveness. 


\section{Acknowledgments}

We extend special thanks to Wei Huang from Zhejiang Province Chinese Medical Hospital, Le Gao, Ji-Chun Yang and Yang Xu from Peking University Health Science Center as well as Jun-Wen Zhou from the Public Health Department, and Aix-Marseille University for their contribution in conducting the literature review and drafting figures for this manuscript. We would like to thank Li Wang from Peking University First Hospital and Yuan Zhang from McMaster University for expert consultation. This study was funded by UCB China Inc. At no point did UCB China Inc. attempt to influence the manuscript. The abstract of this paper was presented as a poster in the ISPE's 11th Asian Conference on Pharmacoepidemiology with interim findings.

\section{Disclosure}

The authors report no conflicts of interest in this work.

\section{References}

1. Beghi E. Addressing the burden of epilepsy: many unmet needs. Pharmacol Res. 2016;107:79-84.

2. Fiest KM, Sauro KM, Wiebe S, et al. Prevalence and incidence of epilepsy: a systematic review and meta-analysis of international studies. Neurology. 2017;88(3):296-303.

3. Olesen J, Gustavsson A, Svensson M, et al. The economic cost of brain disorders in Europe. Eur J Neurol. 2012;19(1):155-162.

4. Begley CE, Durgin TL. The direct cost of epilepsy in the United States: a systematic review of estimates. Epilepsia. 2015;56(9):1376-1387.

5. Kortland LM, Alfter A, Bähr O, et al. Costs and cost-driving factors for acute treatment of adults with status epilepticus: a multicenter cohort study from Germany. Epilepsia. 2016;57(12):2056-2066.

6. Willems LM, Richter S, Watermann N, et al. Trends in resource utilization and prescription of anticonvulsants for patients with active epilepsy in Germany from 2003 to 2013 - a ten-year overview. Epilepsy Behav 2018;83:28-35.

7. Epilepsies: diagnosis and management (clinical guideline [CG137]). Available from: https://www.nice.org.uk/guidance/cg137. Accessed July 18, 2017.

8. Zhu F, Lang SY, Wang XQ, et al. Long-term effectiveness of antiepileptic drug monotherapy in partial epileptic patients: a 7-year study in an epilepsy center in China. Chin Med J. 2015;128(22):3015-3022.

9. Matagne A, Margineanu DG, Kenda B, Michel P, Klitgaard H. Anticonvulsive and anti-epileptic properties of brivaracetam (ucb 34714), a high-affinity ligand for the synaptic vesicle protein, SV2A. $\mathrm{Br} J$ Pharmacol. 2008;154(8):1662-1671.

10. Rigo JM, Hans G, Nguyen L, et al. The anti-epileptic drug levetiracetam reverses the inhibition by negative allosteric modulators of neurona GABA- and glycine-gated currents. Br J Pharmacol. 2002;136(5): 659-672.

11. Deshpande LS, Delorenzo RJ. Mechanisms of levetiracetam in the control of status epilepticus and epilepsy. Front Neurol. 2014;5:11.

12. Emswiler MP, Cumpston KL. Second generation anticonvulsants: gabapentin, lamotrigine, levetiracetam, and topiramate. Available from: https://www.researchgate.net/publication/312660054_Second_ Generation_Anticonvulsants_Gabapentin_Lamotrigine_Levetiracetam_and_Topiramate?ev=auth_pub. Accessed July 18, 2017.

13. French J, Edrich P, Cramer JA. A systematic review of the safety profile of levetiracetam: a new antiepileptic drug. Epilepsy Res. 2001; 47(1-2):77-90.
14. Spencer D. Levetiracetam in men with epilepsy: testosterone is left alone but sperm count is paramount. Epilepsy Curr. 2017;17(2):99-100.

15. Fagan A, Fuld J, Soon E. Levetiracetam-induced eosinophilic pneumonia. BMJ Case Rep. 2017;2017;bcr2016219121.

16. Kim J, Shin JW. Levetiracetam-induced thrombocytopenia in a patient with status epilepticus. Epileptic Disord. 2017;19(1):104-108.

17. di Lorenzo R, Li Y. Rhabdomyolysis associated with levetiracetam administration. Muscle Nerve. 2017;56(1):E1-E2.

18. Shea BJ, Grimshaw JM, Wells GA, et al. Development of AMSTAR: a measurement tool to assess the methodological quality of systematic reviews. BMC Med Res Methodol. 2007;7(1):10.

19. Higgins JP, Altman DG, Gøtzsche PC, et al. The Cochrane Collaboration's tool for assessing risk of bias in randomised trials. BMJ. 2011; 343:d5928.

20. Wells GA, Shea B, O'Connell D. The Newcastle-Ottawa Scale (NOS) for assessing the quality of nonrandomised studies in meta-analyses. Available from: http://www.ohri.ca/programs/clinical_epidemiology/ oxford.asp. Accessed July 18, 2017.

21. Husereau D, Drummond M, Petrou S, et al. Consolidated Health Economic Evaluation Reporting Standards (CHEERS) statement. Value Health. 2013;16(2):e1-e5.

22. Sirven JI, Fife TD, Wingerchuk DM, Drazkowski JF. Second-generation antiepileptic drugs' impact on balance: a meta-analysis. Mayo Clin Proc. 2007;82(1):40-47.

23. Costa J, Fareleira F, Ascenção R, Borges M, Sampaio C, Vaz-Carneiro A. Clinical comparability of the new antiepileptic drugs in refractory partial epilepsy: a systematic review and meta-analysis. Epilepsia. 2011; 52(7):1280-1291.

24. Lo BW, Kyu HH, Jichici D, Upton AM, Akl EA, Meade MO. Metaanalysis of randomized trials on first line and adjunctive levetiracetam. Can J Neurol Sci. 2011;38(3):475-486.

25. Han H, Qu W, Kang H, et al. Effect of second-generation antiepileptic drugs on diplopia: a meta-analysis of placebo-controlled studies. J Huazhong Univ Sci Technolog Med Sci. 2012;32(4):557-562.

26. Maguire M, Marson AG, Ramaratnam S. Epilepsy (generalized). BMJ Clin Evid. 2012;2012:1201.

27. Mbizvo GK, Dixon P, Hutton JL, Marson AG. Levetiracetam add-on for drug-resistant focal epilepsy: an updated Cochrane Review. Cochrane Database Syst Rev. 2012;9(9):CD001901

28. Piedad J, Rickards H, Besag FM, Cavanna AE. Beneficial and adverse psychotropic effects of antiepileptic drugs in patients with epilepsy: a summary of prevalence, underlying mechanisms and data limitations. CNS Drugs. 2012;26(4):319-335.

29. Arya R, Glauser TA. Pharmacotherapy of focal epilepsy in children: a systematic review of approved agents. CNS Drugs. 2013;27(4): 273-286.

30. Bodalia PN, Grosso AM, Sofat R, et al. Comparative efficacy and tolerability of anti-epileptic drugs for refractory focal epilepsy: systematic review and network meta-analysis reveals the need for long term comparator trials. Br J Clin Pharmacol. 2013;76(5):649-667.

31. Fang Y, Wu X, Xu L, et al. Randomized-controlled trials of levetiracetam as an adjunctive therapy in epilepsy of multiple seizure types. J Clin Neurosci. 2014;21(1):55-62.

32. Halma E, de Louw AJ, Klinkenberg S, Aldenkamp AP, Ijff DM, Majoie M. Behavioral side-effects of levetiracetam in children with epilepsy: a systematic review. Seizure. 2014;23(9):685-691.

33. Mbizvo GK, Dixon P, Hutton JL, Marson AG. The adverse effects profile of levetiracetam in epilepsy: a more detailed look. Int J Neurosci. 2014;124(9):627-634.

34. Fountoulakis KN, Gonda X, Baghai TC, et al. Report of the WPA section of pharmacopsychiatry on the relationship of antiepileptic drugs with suicidality in epilepsy. Int J Psychiatry Clin Pract. 2015; 19(3):158-167.

35. Verrotti A, Prezioso G, di Sabatino F, Franco V, Chiarelli F, Zaccara G. The adverse event profile of levetiracetam: a meta-analysis on children and adults. Seizure. 2015;31:49-55. 
36. Weijenberg A, Brouwer OF, Callenbach PM. Levetiracetam monotherapy in children with epilepsy: a systematic review. CNS Drugs. 2015; 29(5):371-382.

37. Campos MS, Ayres LR, Morelo MR, Marques FA, Pereira LR. Efficacy and tolerability of antiepileptic drugs in patients with focal epilepsy: systematic review and network meta-analyses. Pharmacotherapy. 2016;36(12):1255-1271.

38. Egunsola O, Choonara I, Sammons HM. Safety of levetiracetam in paediatrics: a systematic review. PLoS One. 2016;11(3):e0149686.

39. Weston J, Bromley R, Jackson CF, et al. Monotherapy treatment of epilepsy in pregnancy: congenital malformation outcomes in the child. Cochrane Database Syst Rev. 2016;11:CD010224.

40. Zhang L, Li S, Li H, Zou X. Levetiracetam vs. brivaracetam for adults with refractory focal seizures: a meta-analysis and indirect comparison. Seizure. 2016;39:28-33.

41. Geng H, Wang C. Efficacy and safety of oxcarbazepine in the treatment of children with epilepsy: a meta-analysis of randomized controlled trials. Neuropsychiatr Dis Treat. 2017;13:685-695.

42. Song JM, Hahn J, Kim SH, Chang MJ. Efficacy of treatments for infantile spasms: a systematic review. Clin Neuropharmacol. 2017;40(2): 63-84.

43. Mchugh DC, Lancaster S, Manganas LN. A systematic review of the efficacy of levetiracetam in neonatal seizures. Neuropediatrics. 2018; 49(1):012-017.

44. Mohd-Tahir NA, Li SC. Meta-analyses of newer antiepileptic drugs as adjunct for treatment of focal epilepsy in children. Epilepsy Res. 2018;139:113-122.

45. Nevitt SJ, Sudell M, Weston J, Tudur Smith C, Marson AG. Antiepileptic drug monotherapy for epilepsy: a network meta-analysis of individual participant data. Cochrane Database Syst Rev. 2017;6: CD011412.

46. Rosati A, Ilvento L, Lucenteforte E, et al. Comparative efficacy of antiepileptic drugs in children and adolescents: a network meta-analysis. Epilepsia. 2018;59(2):297-314.

47. Veroniki AA, Cogo E, Rios P, et al. Comparative safety of antiepileptic drugs during pregnancy: a systematic review and network meta-analysis of congenital malformations and prenatal outcomes. BMC Med. 2017;15(1):95

48. Veroniki AA, Rios P, Cogo E, et al. Comparative safety of antiepileptic drugs for neurological development in children exposed during pregnancy and breast feeding: a systematic review and network metaanalysis. BMJ Open. 2017;7(7):e017248.

49. Zhang L, Wang C, Li W. A meta-analysis of randomized controlled trials on levetiracetam in the treatment of pediatric patients with epilepsy. Neuropsychiatr Dis Treat. 2018;14:769-779.

50. Zhao T, Feng X, Liu J, Gao J, Zhou C. Evaluate the efficacy and safety of anti-epileptic medications for partial seizures of epilepsy: a network meta-analysis. J Cell Biochem. 2017;118(9):2850-2864.

51. Zhu LN, Chen D, Xu D, Tan G, Wang HJ, Liu L. Newer antiepileptic drugs compared to levetiracetam as adjunctive treatments for uncontrolled focal epilepsy: an indirect comparison. Seizure. 2017;51: 121-132.

52. Berkovic SF, Knowlton RC, Leroy RF, Schiemann J, Falter U; Levetiracetam N01057 Study Group. Placebo-controlled study of levetiracetam in idiopathic generalized epilepsy. Neurology. 2007;69(18):1751-1760.

53. Brodie MJ, Perucca E, Ryvlin P, Ben-Menachem E, Meencke HJ; Levetiracetam Monotherapy Study Group. Comparison of levetiracetam and controlled-release carbamazepine in newly diagnosed epilepsy. Neurology. 2007;68(6):402-408.

54. Coppola G, Franzoni E, Verrotti A, et al. Levetiracetam or oxcarbazepine as monotherapy in newly diagnosed benign epilepsy of childhood with centrotemporal spikes (BECTS): an open-label, parallel group trial. Brain Dev. 2007;29(5):281-284.

55. Noachtar S, Andermann E, Meyvisch P, et al. Levetiracetam for the treatment of idiopathic generalized epilepsy with myoclonic seizures. Neurology. 2008;70(8):607-616.
56. Zhou B, Zhang Q, Tian L, Xiao J, Stefan H, Zhou D. Effects of levetiracetam as an add-on therapy on cognitive function and quality of life in patients with refractory partial seizures. Epilepsy Behav. 2008;12(2): 305-310.

57. Labiner DM, Ettinger AB, Fakhoury TA, et al. Effects of lamotrigine compared with levetiracetam on anger, hostility, and total mood in patients with partial epilepsy. Epilepsia. 2009;50(3):434-442.

58. Levisohn PM, Mintz M, Hunter SJ, Yang H, Jones J; N01103 Levetiracetam Study Group. Neurocognitive effects of adjunctive levetiracetam in children with partial-onset seizures: a randomized, double-blind, placebo-controlled, noninferiority trial. Epilepsia. 2009;50(11): 2377-2389.

59. Lim DA, Tarapore P, Chang E, et al. Safety and feasibility of switching from phenytoin to levetiracetam monotherapy for glioma-related seizure control following craniotomy: a randomized Phase II pilot study. J Neurooncol. 2009;93(3):349-354.

60. Peltola J, Coetzee C, Jiménez F, et al. Once-daily extended-release levetiracetam as adjunctive treatment of partial-onset seizures in patients with epilepsy: a double-blind, randomized, placebo-controlled trial. Epilepsia. 2009;50(3):406-414.

61. Piña-Garza JE, Nordli DR, Rating D, et al. Adjunctive levetiracetam in infants and young children with refractory partial-onset seizures. Epilepsia. 2009;50(5):1141-1149.

62. Wu XY, Hong Z, Wu X, et al. Multicenter double-blind, randomized, placebo-controlled trial of levetiracetam as add-on therapy in Chinese patients with refractory partial-onset seizures. Epilepsia. 2009;50(3):398-405.

63. Xiao Z, Li JM, Wang XF, et al. Efficacy and safety of levetiracetam $(3,000 \mathrm{mg} /$ day $)$ as an adjunctive therapy in Chinese patients with refractory partial seizures. Eur Neurol. 2009;61(4):233-239.

64. Cumbo E, Ligori LD. Levetiracetam, lamotrigine, and phenobarbital in patients with epileptic seizures and Alzheimer's disease. Epilepsy Behav. 2010;17(4):461-466.

65. de La Loge C, Hunter SJ, Schiemann J, Yang H. Assessment of behavioral and emotional functioning using standardized instruments in children and adolescents with partial-onset seizures treated with adjunctive levetiracetam in a randomized, placebo-controlled trial. Epilepsy Behav. 2010;18(3):291-298.

66. UCB Japan Co. Ltd. A double-blind, placebo-controlled study of levetiracetam in epilepsy patients with generalized tonic-clonic seizures (except partial seizures evolving to secondarily generalized seizures). Available from: https://ClinicalTrials.gov/show/NCT01228747. Accessed July 18, 2017

67. UCB Korea Co., Ltd. Levetiracetam versus topiramate as adjunctive therapy to evaluate efficacy and safety in subjects with refractory partial onset seizures. Available from: https://ClinicalTrials.gov/show/ NCT01229735. Accessed July 18, 2017.

68. Fattore C, Boniver C, Capovilla G, et al. A multicenter, randomized, placebo-controlled trial of levetiracetam in children and adolescents with newly diagnosed absence epilepsy. Epilepsia. 2011;52(4):802-809.

69. Consoli D, Bosco D, Postorino P, et al. Levetiracetam versus carbamazepine in patients with late poststroke seizures: a multicenter prospective randomized open-label study (EpIC Project). Cerebrovasc Dis. 2012;34(4):282-289.

70. Hakami T, Todaro M, Petrovski S, et al. Substitution monotherapy with levetiracetam vs older antiepileptic drugs: a randomized comparative trial. Arch Neurol. 2012;69(12):1563-1571.

71. Rosenow F, Schade-Brittinger C, Burchardi N, et al. The LaLiMo Trial: lamotrigine compared with levetiracetam in the initial 26 weeks of monotherapy for focal and generalised epilepsy - an open-label, prospective, randomised controlled multicenter study. J Neurol Neurosurg Psychiatry. 2012;83(11):1093-1098.

72. Borggraefe I, Bonfert M, Bast T, et al. Levetiracetam vs. sulthiame in benign epilepsy with centrotemporal spikes in childhood: a doubleblinded, randomized, controlled trial (German HEAD Study). Eur J Paediatr Neurol. 2013;17(5):507-514. 
73. UCB Pharma SA. Open-label, randomized, active-controlled study of LEV used as monotherapy in patients with partial-onset seizures. Available from: https://ClinicalTrials.gov/show/NCT01954121. Accessed July 18, 2017.

74. Trinka E, Marson AG, van Paesschen W, et al. KOMET: an unblinded, randomised, two parallel-group, stratified trial comparing the effectiveness of levetiracetam with controlled-release carbamazepine and extended-release sodium valproate as monotherapy in patients with newly diagnosed epilepsy. J Neurol Neurosurg Psychiatry. 2013;84(10): 1138-1147.

75. University of Rochester. A safety and feasibility study of enteral LVT vs. standard of care for seizure control in pediatric CM (LVT2). Available from: https://ClinicalTrials.gov/show/NCT01982812. Accessed July 18, 2017.

76. Rossetti AO, Jeckelmann S, Novy J, Roth P, Weller M, Stupp R. Levetiracetam and pregabalin for antiepileptic monotherapy in patients with primary brain tumors. A Phase II randomized study. Neuro Oncol. 2014;16(4):584-588.

77. Zaccara G, Almas M, Pitman V, Knapp L, Posner H. Efficacy and safety of pregabalin versus levetiracetam as adjunctive therapy in patients with partial seizures: a randomized, double-blind, noninferiority trial. Epilepsia. 2014;55(7):1048-1057.

78. Inoue Y, Yagi K, Ikeda A, et al. Efficacy and tolerability of levetiracetam as adjunctive therapy in Japanese patients with uncontrolled partialonset seizures. Psychiatry Clin Neurosci. 2015;69(10):640-648.

79. Jung DE, Yu R, Yoon JR, et al. Neuropsychological effects of levetiracetam and carbamazepine in children with focal epilepsy. Neurology. 2015;84(23):2312-2319.

80. Suresh SH, Chakraborty A, Virupakshaiah A, Kumar N. Efficacy and safety of levetiracetam and carbamazepine as monotherapy in partial seizures. Epilepsy Res Treat. 2015;2015(4):1-6.

81. Werhahn KJ, Trinka E, Dobesberger J, et al. A randomized, doubleblind comparison of antiepileptic drug treatment in the elderly with new-onset focal epilepsy. Epilepsia. 2015;56(3):450-459.

82. Hakami T, O’Brien TJ, Petty SJ, et al. Monotherapy with levetiracetam versus older AEDs: a randomized comparative trial of effects on bone health. Calcif Tissue Int. 2016;98(6):556-565.

83. Kim JH, Lee SK, Loesch C, et al. Comparison of levetiracetam and oxcarbazepine monotherapy among Korean patients with newly diagnosed focal epilepsy: a long-term, randomized, open-label trial. Epilepsia. 2017;58(4):e70-e74.

84. Tacke M, Gerstl L, Heinen F, et al. Effect of anticonvulsive treatment on neuropsychological performance in children with BECTS. Eur $J$ Paediatr Neurol. 2016;20(6):874-879.

85. Siniscalchi A, Scaglione F, Sanzaro E, et al. Effects of phenobarbital and levetiracetam on PR and QTc intervals in patients with post-stroke seizure. Clin Drug Investig. 2014;34(12):879-886.

86. Bootsma HP, Ricker L, Diepman L, et al. Long-term effects of levetiracetam and topiramate in clinical practice: a head-to-head comparison. Seizure. 2008;17(1):19-26.

87. Andersohn F, Schade R, Willich SN, Garbe E. Use of antiepileptic drugs in epilepsy and the risk of self-harm or suicidal behavior. Neurology. 2010;75(4):335-340.

88. Arif H, Buchsbaum R, Pierro J, et al. Comparative effectiveness of 10 antiepileptic drugs in older adults with epilepsy. Arch Neurol. 2010; 67(4):408-415.

89. Merrell RT, Anderson SK, Meyer FB, Lachance DH. Seizures in patients with glioma treated with phenytoin and levetiracetam. J Neurosurg. 2010;113(6):1176-1181

90. Rauchenzauner M, Bitsche G, Svalheim S, et al. Effects of levetiracetam and valproic acid monotherapy on sex-steroid hormones in prepubertal children - results from a pilot study. Epilepsy Res. 2010;88(2-3): 264-268.

91. Veiby G, Daltveit AK, Engelsen BA, Gilhus NE. Fetal growth restriction and birth defects with newer and older antiepileptic drugs during pregnancy. J Neurol. 2014;261(3):579-588.
92. Xiao F, An D, Deng H, Chen S, Ren J, Zhou D. Evaluation of levetiracetam and valproic acid as low-dose monotherapies for children with typical benign childhood epilepsy with centrotemporal spikes (BECTS). Seizure. 2014;23(9):756-761

93. Javed A, Cohen B, Detyniecki K, et al. Rates and predictors of patientreported cognitive side effects of antiepileptic drugs: an extended follow-up. Seizure. 2015;29:34-40.

94. Tinchon A, Oberndorfer S, Marosi C, et al. Haematological toxicity of valproic acid compared to levetiracetam in patients with glioblastoma multiforme undergoing concomitant radio-chemotherapy: a retrospective cohort study. J Neurol. 2015;262(1):179-186.

95. Tomson T, Battino D, Bonizzoni E, et al. Antiepileptic drugs and intrauterine death: a prospective observational study from EURAP. Neurology. 2015;85(7):580-588.

96. Bektaş G, Tekin U, Özkan MU, et al. The influence of levetiracetam on psychosocial and behavioral functioning in children: a case-control and follow-up study. Epilepsy Behav. 2017;72:39-42.

97. Chen B, Choi H, Hirsch LJ, et al. Psychiatric and behavioral side effects of antiepileptic drugs in adults with epilepsy. Epilepsy Behav. 2017;76:24-31.

98. Egunsola O, Choonara I, Sammons HM, Whitehouse WP. Safety of antiepileptic drugs in children and young people: a prospective cohort study. Seizure. 2018;56:20-25.

99. Frey N, Bodmer M, Bircher A, et al. The risk of Stevens-Johnson syndrome and toxic epidermal necrolysis in new users of antiepileptic drugs. Epilepsia. 2017;58(12):2178-2185.

100. Lee T, Warrick BJ, Sarangarm P, et al. Levetiracetam in toxic seizures. Clin Toxicol (Phila). 2018;56(3):175-181.

101. Maschio M, Zarabla A, Maialetti A, et al. Quality of life, mood and seizure control in patients with brain tumor related epilepsy treated with lacosamide as add-on therapy: a prospective explorative study with a historical control group. Epilepsy Behav. 2017;73:83-89.

102. Shih FY, Chuang YC, Chuang MJ, et al. Effects of antiepileptic drugs on thyroid hormone function in epilepsy patients. Seizure. 2017;48:7-10.

103. Stephen LJ, Wishart A, Brodie MJ. Psychiatric side effects and antiepileptic drugs: observations from prospective audits. Epilepsy Behav. 2017;71(Pt A):73-78.

104. Newsome SD, Xue LY, Jennings T, Castaneda GY. Levetiracetaminduced diffuse interstitial lung disease. J Child Neurol. 2007;22(5) $628-630$.

105. Gallerani M, Mari E, Boari B, Carletti R, Marra A, Cavallo M. Pancytopenia associated with levetiracetam treatment. Clin Drug Investig 2009;29(11):747-751.

106. Hacquard M, Richard S, Lacour JC, Lecompte T, Vespignani H. Levetiracetam-induced platelet dysfunction. Epilepsy Res. 2009; 86(1):94-96.

107. Hurwitz KA, Ingulli EG, Krous HF. Levetiracetam induced interstitial nephritis and renal failure. Pediatr Neurol. 2009;41(1):57-58.

108. Peer Mohamed B, Mohamed BP, Prabhakar P. Thrombocytopenia as an adverse effect of levetiracetam therapy in a child. Neuropediatrics. 2009;40(5):243-244.

109. Tamarelle C, Pandit F, Mazarati A, Riquet A, Vallée L, Auvin S. Levetiracetam-induced depression in a 5-year-old child with partial epilepsy. Seizure. 2009;18(3):235-236.

110. vande Griend JP, Linnebur SA, Bainbridge JL. Probable levetiracetamassociated depression in the elderly: two case reports. Am J Geriatr Pharmacother. 2009;7(5):281-284.

111. Broli M, Provini F, Naldi I, et al. Unexpected gamma glutamyltransferase rise increase during levetiracetam monotherapy. Epileptic Disord. 2010;12(1):81-82.

112. Caraballo RH, Cersósimo R, de Los Santos C. Levetiracetam-induced seizure aggravation associated with continuous spikes and waves during slow sleep in children with refractory epilepsies. Epileptic Disord. 2010;12(2):146-150.

113. Oghlakian R, Nock C, Koubeissi M. A case of levetiracetam-induced thrombocytopenia. Epileptic Disord. 2010;12(4):335-337. 
114. Sahaya K, Goyal MK, Sarwal A, Singh NN. Levetiracetam-induced thrombocytopenia among inpatients: a retrospective study. Epilepsia. 2010;51(12):2492-2495.

115. Bachmann T, Bertheussen KH, Svalheim S, et al. Haematological side effects of antiepileptic drug treatment in patients with epilepsy. Acta Neurol Scand Suppl. 2011;191(191):23-27.

116. Givon L, Porter S, Padmanabhan B, Goren J, Cohen PA. Levetiracetam, seizures, and suicidality. Harv Rev Psychiatry. 2011;19(1):47-55.

117. Alkhotani A, Mclachlan RS. Levetiracetam induced angioedema in a patient with previous anticonvulsant hypersensitivity reaction to phenytoin and lamotrigine. Seizure. 2012;21(5):407-408.

118. Babtain FA. Levetiracetam may worsen myoclonus in patients with juvenile myoclonic epilepsy: case reports. Clin Neuropharmacol. 2012;35(4):201-202.

119. Bishop-Freeman SC, Kornegay NC, Winecker RE. Postmortem levetiracetam $\left(\right.$ Keppra $\left.^{\mathbb{E}}\right)$ data from North Carolina. J Anal Toxicol. 2012;36(6):422-428.

120. Calabrò RS, Italiano D, Militi D, Bramanti P. Levetiracetam-associated loss of libido and anhedonia. Epilepsy Behav. 2012;24(2):283-284.

121. Camacho A, Espín JC, Nuñez N, Simón R. Levetiracetam-induced reversible autistic regression. Pediatr Neurol. 2012;47(1):65-67.

122. Chau K, Yong J, Ismail K, Griffith N, Liu M, Makris A. Levetiracetaminduced severe acute granulomatous interstitial nephritis. Clin KidneyJ. 2012;5(3):234-236.

123. Gómez-Zorrilla S, Ferraz AV, Pedrós C, Lemus M, Peña C. Levetiracetam-induced drug reaction with eosinophilia and systemic symptoms syndrome. Ann Pharmacother. 2012;46(7-8):e20.

124. Xiong N, Hou L, Lu N, Mohamed AA, Wang T, Huang Y. Probable levetiracetam-related serum alkaline phosphatase elevation. BMC Neurol. 2012;12:97.

125. Zou LP, Ding CH, Song ZJ, Li XF. Stevens-Johnson syndrome induced by levetiracetam. Seizure. 2012;21(10):823-825.

126. Hommet C, Beaufils E, Roubeau V, et al. Encephalopathy induced by levetiracetam in an elderly woman. Aging Clin Exp Res. 2013;25(1): 111-113.

127. Karadag AS, Bilgili SG, Calka O, Onder S, Kosem M, BurakgaziDalkilic E. A case of levetiracetam induced bullous pemphigoid. Cutan Ocul Toxicol. 2013;32(2):176-178.

128. Kaufman KR, Bisen V, Zimmerman A, Tobia A, Mani R, Wong S. Apparent dose-dependent levetiracetam-induced de novo major depression with suicidal behavior. Epilepsy Behav Case Rep. 2013;1: 110-112.

129. Metin SZ, Ozmen M, Ozkara C, Ozmen E. Hypersexuality in a patient with epilepsy during treatment of levetiracetam. Seizure. 2013;22(2): 151-152.

130. Sethi NK, Sethi PK, Torgovnick J, Arsura E, Cukierwar F. Asymptomatic elevation of liver enzymes due to levetiracetam: a case report. Drug Metabol Drug Interact. 2013;28(2):123-124.

131. Akiyama H, Haga Y, Sasaki N, Yanagisawa T, Hasegawa Y. A case of rhabdomyolysis in which levetiracetam was suspected as the cause. Epilepsy Behav Case Rep. 2014;2:152-155.

132. Aksoy D, Cevik B, Kurt S, Pekdas E, Solmaz V. Hypokalemia and hypomagnesaemia related to levetiracetam use. J Clin Neurosci. 2014;21(11):1989-1990.

133. Azar NJ, Aune P. Acute pancreatitis and elevated liver transaminases after rapid titration of oral levetiracetam. J Clin Neurosci. 2014; 21(6):1053-1054.

134. Bui M, Baslet G, Weisholtz D, Mcelrath T. Levetiracetam-induced psychosis in a pregnant woman with prior substance abuse. Harv Rev Psychiatry. 2014;22(3):193-200.

135. Hwang ES, Siemianowski LA, Sen S, Patel R. Levetiracetam: an unusual cause of delirium. Am J Ther. 2014;21(6):e225-e228.

136. Isaacson JE, Choe DJ, Doherty MJ. Creatine phosphokinase elevation exacerbated by levetiracetam therapy. Epilepsy Behav Case Rep. 2014;2:189-191.

137. Koklu E, Ariguloglu EA, Koklu S. Levetiracetam-induced anaphylaxis in a neonate. Pediatr Neurol. 2014;50(2):192-194.
138. Kumar N, Swaroop HS, Chakraborty A, Chandran S. Levetiracetam induced acute reversible psychosis in a patient with uncontrolled seizures. Indian J Pharmacol. 2014;46(5):560-561.

139. Park EM, Holmes JA, Reeder-Hayes KE. Acute mania associated with levetiracetam treatment. Psychosomatics. 2014;55(1):98-100.

140. Spengler DC, Montouris GD, Hohler AD. Levetiracetam as a possible contributor to acute kidney injury. Clin Ther. 2014;36(8):1303-1306.

141. Zaki SA, Gupta S. Levetiracetam-induced acute psychosis in a child. Indian J Pharmacol. 2014;46(3):341-342.

142. Zou X, Hong Z, Zhou D. Hair loss with levetiracetam in five patients with epilepsy. Seizure. 2014;23(2):158-160.

143. Arı H, Kahraman F, Acaban MB. The first case of levetiracetaminduced and tolvaptan-resistant hyponatremia. Turk Kardiyol Dern Ars. 2015;43(3):284-287.

144. Eleni K. Dress syndrome induced by levetiracetam. J Eur Acad Dermatol Venereol. 2015;29(2):377-378.

145. Flannery AH, Willey MD, Thompson Bastin ML, Buch KP, Bensadoun ES. Eosinophilia and fever with levetiracetam: a case report. Pharmacotherapy. 2015;35(8):e131-e135

146. Fujikawa M, Kishimoto Y, Kakisaka Y, et al. Obsessive-compulsive behavior induced by levetiracetam. J Child Neurol. 2015;30(7):942-944.

147. Gencler OS, Gencler B, Altunel CT, Arslan N. Levetiracetam induced psoriasiform drug eruption: a rare case report. Saudi Pharm J. 2015; 23(6):720-722.

148. Kawakami Y, Okazaki T, Takase M, Fujino O, Itoh Y. A girl with idiopathic epilepsy showing forced normalization after levetiracetam administration. J Nippon Med Sch. 2015;82(5):250-253.

149. Makke Y, Hmaimess G, Nasreddine W, Fawaz A, Beydoun A. Paradoxical exacerbation of myoclonic-astatic seizures by levetiracetam in myoclonic astatic epilepsy. BMC Pediatr. 2015;15:6.

150. Molokwu OA, Ezeala-Adikaibe BA, Onwuekwe IO. Levetiracetaminduced rage and suicidality: two case reports and review of literature. Epilepsy Behav Case Rep. 2015;4:79-81.

151. Peyrl A, Weichert N, Kühl JS, Ebell W, Hernáiz Driever P. Levetiracetam as a possible cause of secondary graft failure after allogenic hematopoietic stem cell transplantation. Eur J Paediatr Neurol. 2015; 19(1):75-77.

152. Taberner Bonastre MT, Peralta Muñoz S, Boza FM, Gumà I Padró J. Neutropenia secondary to exposure to levetiracetam. Tumori. 2015; 101(5):145-146.

153. Bayram AK, Canpolat M, Çınar SL, et al. Drug reaction with eosinophilia and systemic symptoms syndrome induced by levetiracetam in a pediatric patient. J Emerg Med. 2016;50(2):e61-e66.

154. Dar WR, Sofi N, Latief M, Dar IA, Kasana BA. Levetiracetam induced drug reaction with eosinophilia and systemic symptom syndrome. Indian J Dermatol. 2016;61(2):235.

155. García Carretero R, Romero Brugera M, Olid-Velilla M, SalamancaRamirez I. Pancytopenia associated with levetiracetam in an epileptic woman. BMJ Case Rep. 2016;2016:bcr2016217407.

156. Jones RT, Evans W, Mersfelder TL, Kavanaugh K. Rare red rashes: a case report of levetiracetam-induced cutaneous reaction and review of the literature. Am J Ther. 2016;23(3):e944-e946.

157. Ju J, Zou LP, Shi XY, Hu LY, Pang LY. Levetiracetam: probably associated diurnal frequent urination. Am J Ther. 2016;23(2):e624-e627.

158. Turati M, Glard Y, Afonso D, Griffet J, Bigoni M. Osteochondral alteration in a child treated with levetiracetam: a rare case of juvenile osteochondritis dissecans of the talar head. J Pediatr Orthop B. 2017; 26(2):189-192.

159. Kubota K, Yamamoto T, Kawamoto M, et al. Levetiracetam-induced rhabdomyolysis: a case report and literature review. Neurol Asia. 2017;22:275-278.

160. Ozdemir H, Sumer S, Karabagli H, et al. B cell aplasia and hypogammaglobulinemia associated with levetiracetam. Ann Saudi Med. 2018;38(1):545-548.

161. Sereflican B, Karapinar T, Duzcu SE, Turkoglu ŞA. Disseminated eruptive granuloma annulare induced by levetiracetam. Cutan Ocul Toxicol. 2017;36(3):300-301. 
162. Beghi E, Atzeni L, Garattini L. Economic analysis of newer antiepileptic drugs. CNS Drugs. 2008;22(10):861-875.

163. Suh GH, Lee SK. Economic evaluation of add-on levetiracetam for the treatment of refractory partial epilepsy in Korea. Psychiatry Investig. 2009;6(3):185-193.

164. Tomson T, Battino D, Bonizzoni E, et al. Comparative risk of major congenital malformations with eight different antiepileptic drugs: a prospective cohort study of the EURAP registry. Lancet Neurol. 2018;17(6):530-538.

165. Kim J, Kondratyev A, Gale K. Antiepileptic drug-induced neuronal cell death in the immature brain: effects of carbamazepine, topiramate, and levetiracetam as monotherapy versus polytherapy. J Pharmacol Exp Ther. 2007;323(1):165-173.

166. Cumbo E, Ligori LD. Levetiracetam, lamotrigine, and phenobarbital in patients with epileptic seizures and Alzheimer's disease. Epilepsy Behav. 2010;17(4):461-466.

167. Chan R, Wei CY, Chen YT, Benet LZ. Use of the Biopharmaceutics Drug Disposition Classification System (BDDCS) to help predict the occurrence of idiosyncratic cutaneous adverse drug reactions associated with antiepileptic drug usage. AAPS J. 2016;18(3):757-766.
168. Fong JK, Chan EL, Leung H, et al. An update of the Hong Kong Epilepsy Guideline: consensus statement on the use of antiepileptic drugs in Hong Kong. Hong Kong Med J. 2017;23(1):74-88.

169. Wijnen BFM, van Mastrigt G, Evers S, et al. A systematic review of economic evaluations of treatments for patients with epilepsy. Epilepsia. 2017;58(5):706-726.

170. Kazerooni R, Bounthavong M. Cost-effectiveness analysis of intravenous levetiracetam versus intravenous phenytoin for early onset seizure prophylaxis after neurosurgery and traumatic brain injury. Clinicoecon Outcomes Res. 2010;2:15-23.

171. Lyttle MD, Gamble C, Messahel S, et al. Emergency treatment with levetiracetam or phenytoin in status epilepticus in children - the EcLiPSE study: study protocol for a randomised controlled trial. Trials. 2017;18(1):283.

172. Bähr $\mathrm{O}$, Hermisson $\mathrm{M}$, Rona S, et al. Intravenous and oral levetiracetam in patients with a suspected primary brain tumor and symptomatic seizures undergoing neurosurgery: the HELLO trial. Acta Neurochir (Wien). 2012;154(2):229-235.

173. Kellinghaus C, Stögbauer F. Treatment of status epilepticus in a large community hospital. Epilepsy Behav. 2012;23(3):235-240.
Neuropsychiatric Disease and Treatment

\section{Publish your work in this journal}

Neuropsychiatric Disease and Treatment is an international, peerreviewed journal of clinical therapeutics and pharmacology focusing on concise rapid reporting of clinical or pre-clinical studies on a range of neuropsychiatric and neurological disorders. This journa is indexed on PubMed Central, the 'PsycINFO' database and CAS,

\section{Dovepress}

and is the official journal of The International Neuropsychiatric Association (INA). The manuscript management system is completely online and includes a very quick and fair peer-review system, which is all easy to use. Visit http://www.dovepress.com/testimonials.php to read real quotes from published authors. 